\title{
Vejez y envejecimiento: Imaginarios sociales presentes en los textos escolares oficiales del Ministerio de educación chileno
}

Pamela Jorquera

Magíster en Análisis Sistémico aplicado a la Sociedad, Universidad de Chile pjorquera@facso.cl

Resumen

En este documento se analizan los imaginarios sociales presentes en los textos escolares oficiales durante el año 2009 del Ministerio de Educación de Chile, con respecto a la vejez y el envejecimiento y su relación con fenómenos de inclusión y exclusión social. Este análisis consiste en la aplicación del modelo operativo para el estudio de los Imaginarios Sociales del profesor Juan Luis Pintos.

Abstract

This paper examines some social imaginaries in the official textbooks for the year 2009 of the Ministry of Education of Chile, with respect to old age and aging and its relation to phenomena of social inclusion and exclusion. This analysis involves the application of the operational model for the study of social imaginaries developed by Professor Juan Luis Pintos.

Palabras Clave: Vejez, Chile, inclusión, exclusión, educación

Keywords: Aging, Chile, inclusion, exclusion, education

\section{Introducción}

Chile, junto a otros países, ha experimentado un cambio radical en la constitución de su población. "Por un lado la población adulta mayor ha aumentado considerablemente al igual que la esperanza de vida de los chilenos, mientras que por otro lado ha disminuido la tasa de natalidad". (Stevenson; 2002, 3). Según Stevenson, el Censo del año 2002 mostró una disminución porcentual de las personas de 15 años, mientras que los adultos mayores alcanzaban el $11 \%$. Actualmente la población mayor de 60 años corresponde al $13 \%$ de la población y se espera que para el 2050 aumente a un $28,2 \%$ (Arnold, Thumala, Urquiza y Ojeda; 2009).

Lo anterior, así como las nuevas situaciones que debe enfrentar la sociedad con respecto a la vejez y el envejecimiento, vuelve necesario precisar cómo serán observados y entendidos. La forma de tratar la vejez y envejecimiento, dependerá de la sociedad en la que se manifiesten, "la vejez no será sino lo que quiera que sea la sociedad que la crea" (Aranibar: 2001, 10). En la construcción de dichos fenómenos cumplie un papel importante las imágenes o imaginarios que circulen en la sociedad sobre ellos. En este sentido, los hallazgos de los estudios realizados (Abarca; 1993, Gastrom, Vujosevich y Oddone; 2003, Vera, Rojas, Moya, Godoy, Salinas, Duarte y Cartes; 2004, Okoye; 2004, Monchietti y Sánchez; 2008, Urquiza, Thumala, Arnold, Ojeda y Vogel; 2008) muestran que, tanto en América como en Europa, los 
imaginarios o representaciones sociales acerca de la vejez y el envejecimiento tienen un carácter predominantemente negativo, la mayor parte refiere a que las personas adultas mayores son pasivas y dependientes de los demás, mostrándolas como personas obsoletas, inactivas y dependientes.

La bibliografía revisada señala que, en general las representaciones positivas de los adultos mayores son escasas, salvo excepciones como un estudio hecho en China (Tan, Zhang \& Fan; 2004), el cual revela que los jóvenes de ese país tienen actitudes positivas o neutrales hacia la vejez. De esta manera se advierte un escenario mundial en donde predominan las representaciones negativas de la vejez y el envejecimiento, las que constituyen una discriminación que trasciende a todas las culturas. Por lo que se puede decir que "la tendencia general es percibir la vejez como una etapa en la que se pierden los atributos positivos de la vida" (Arnold, Thumala, Urquiza y Ojeda; 2007, 75)

La importancia de tratar los imaginarios negativos presentes en la sociedad sobre la vejez y el envejecimiento radica en que éstas no sólo se ubican en las generaciones más jóvenes, condicionando su actitud negativa hacia ellas, sino que son traspasadas y asumidas por los mismos adultos mayores, quienes empiezan a representarse a sí mismos como seres indefensos, lo que largo plazo diezma su propia independencia.

Frente a este escenario, surgió la pregunta sobre los procesos o mecanismos mediante los cuales las diferentes sociedades van creando y comunicando los imaginarios sociales sobre la vejez y el envejecimiento. Puesto que "en general las representaciones sociales no sólo se construyen en lo experimentado por cada uno, sino que también de los conocimientos e informaciones que son transmitidas por medio de las tradiciones, educación y la comunicación social" (Monchietti y Sánchez; 2008, 145). Uno de los principales agentes de socialización, después de la familia, a través del cual la sociedad transmite lo que considera primordial en la formación de sus miembros, es el sistema educativo. El cual es considerado como un agente socializador primordial tanto por el objetivo que persigue como por el tiempo que una persona permanece en él (doce años de escolaridad más dos años de educación pre básica en Chile)

Estudios realizados sobre el sistema educativo, muestran como "el elemento más emblemático de su actividad son los textos escolares, ya que representan recursos didácticos que apoyan el proceso de enseñanza-aprendizaje" (Ramírez; 2003, 1) Los textos escolares constituyen una herramienta inseparable de los alumnos por más de la mitad del tiempo que dura el periodo escolar. De ahí la preocupación a nivel mundial por constituir el texto escolar en una unidad de estudio a fin de erradicar de ellos contenidos xenófobos o estereotipos que puedan ser transmitidos a las nuevas generaciones. Ya que el texto escolar sirve para transmitir valores, estereotipos y modelos culturales que refuerzan creencias y actitudes compartidas.

De acuerdo a lo expuesto, los imaginarios comunicados por los textos escolares, durante la permanencia en el sistema educativo de niños y jóvenes, configurarían la forma como esos imaginarios van siendo asumidos y comunicados por ellos mismos, constituyendo una profecía autocumplida que refuerzan procesos de inclusión y exclusión social de los adultos mayores, ya que no sólo están presentes en los niños y jóvenes, sino que son aceptadas como una realidad por los mismos adultos mayores

En este sentido, el supuesto en el cual se basó la presente investigación fue que los imaginarios sociales construidos y comunicados por medio de los textos escolares, 
configurarían ámbitos de exclusión o inclusión de la vejez y el envejecimiento a nuestra sociedad, tanto para las futuras generaciones, como para los mismos adultos mayores.

De acuerdo a lo anterior, la presente investigación tuvo como objetivo general develar los imaginarios sociales presentes en los textos escolares oficiales del año 2009 del Ministerio de Educación chileno (MINEDUC) y su relación con los fenómenos de inclusión y exclusión. Los objetivos específicos definidos fueron: - 1. Identificar y describir los conceptos, temáticas e ilustraciones asociadas a la vejez y envejecimiento en los textos escolares, - 2. Vincular los imaginarios de vejez y envejecimiento presentes en los textos escolares con ámbitos de inclusión y exclusión social y - 3 . Caracterizar los ámbitos de inclusión y exclusión presentes en los imaginarios de vejez y envejecimiento.

\section{Marco teórico}

Después de la revisión de los diferentes estudios realizados sobre los imaginarios o representaciones sociales y sobre la construcción social de la vejez y el envejecimiento presente en la sociedad, es preciso señalar que el enfoque epistemológico y teórico que guió la investigación propuesta, es el programa de observación sociopoietico (Arnold; 2003; 2006) desde el cual se comprende el fenómeno de imaginarios sociales sobre la vejez y envejecimiento, y el enfoque de la Exclusión/Inclusión.

El programa de observación sociopoietico (Op. Cit., 2003, 2006) corresponde a un posicionamiento radical del entendimiento de lo social como constituido por sistemas cerrados y autorreferenciales. El conocimiento desde este enfoque epistemológico no responde a la verdad sobre la existencia de un objeto externo sino que responde a las construcciones que cada sistema haga sobre la "realidad" en base a las observaciones que realice. De esta manera, este enfoque permite y proporciona los procedimientos mediante los cuales observar los esquemas de distinción que operan en las observaciones que cada sistema realiza, este procedimiento es la observación de segundo orden (Arnold; 1998) En este sentido, la observación de segundo orden realizada en esta investigación, para el estudio de los Imaginarios Sociales, permitió identificar las formas de distinción sobre la vejez y el envejecimiento presente en los textos escolares.

Los Imaginarios Sociales, por su parte, fueron entendidos desde lo planteado por Juan Luis Pintos (2000), puesto que su planteamiento es teóricamente coherente con el enfoque epistemológico de la presente investigación. Pintos (2000) define a los Imaginarios Sociales: como aquellos esquemas, construidos socialmente, que nos permiten percibir algo como real, explicarlo e intervenir operativamente en lo que en cada sistema social se considera como realidad. De acuerdo a esto, se puede entender a los Imaginarios Sociales como constructores de un orden social, rigiendo las representaciones colectivas de identificación e integración social. Siguiendo a Pintos, los Imaginarios Sociales operarían al interior de los sistemas como un meta-código, es decir que su operación no remitiría a un sólo sistema, sino que se ubicarían en el campo de la comunicación intersistémica, operando en el campo de la construcción de la realidad. El meta-código mediante el cual operan los Imaginarios Sociales es relevancia/opacidad, en donde la relevancia corresponde al polo positivo del código, aquello que se ve, mientras que la opacidad se refiere al polo negativo del código, es decir aquello que queda fuera de la observación, lo que aparece ocultado u obviado (Op, Cit, . 2000) 
Finalmente, se debe precisar que el fenómeno de la Inclusión/ Exclusión es importante si consideramos, como Niklas Luhmann plantea (Rodríguez y Arnold, 1992), a la sociedad actual como una sociedad funcionalmente diferenciada, en donde la variedad y complejidad alcanzada no es posible de ser soportada socialmente por un único centro, lo que hace imperar las diferencias promovidas por las especializaciones de las operaciones asumidas por diferentes sistemas sociales. Uno de los atributos más importantes presentes en esta sociedad, es el fenómeno conocido como la exclusión; "la exclusión es entendida como la posibilidad de que una parte de la población quede totalmente privada de las prestaciones de los sistemas funcionales, así como que, en el ámbito de la inclusión, se producen formas no previstas de estabilización" (Robles 2003: 3) De este modo podemos ver que las sociedades actuales, y en específico la sociedad chilena, poseen y toleran tanto la inclusión como la exclusión, lo que repercute en la posibilidad de estar incluidos de algunos sistemas y al mismo tiempo excluidos de otros.

Estas perspectivas resultaron adecuadas para estudiar la vejez y envejecimiento puesto que plantean que no hay una sola manera de entenderla y por tanto de observarla. Es así como permitieron observar los Imaginarios Sociales de la vejez y envejecimiento presente en los textos escolares, ver cómo son comunicados por el sistema social y como se vinculan a las diferentes formas de inclusión y exclusión.

Para poder observar los Imaginarios Sociales de la vejez y el envejecimiento presentes en los textos escolares del MINEDUC y su posible vinculación con los procesos de Inclusión y Exclusión descritos, se distinguieron, en base a las investigaciones realizadas, cuatro tipos de manifestaciones de este fenómeno, las que son:

Inclusión/ Exclusión Primaria: referida a la posibilidad de que los individuos, en nuestro caso adultos mayores, puedan o no acceder a los sistemas funcionales (como la economía, educación, política, religión, deporte, tecnología etc.) Esto puede significar su inclusión o exclusión de algunos servicios o prestaciones básicas de estos sistemas funcionales (Robles; 2005). De esa posibilidad dependerá que puedan mantener su adecuada existencia biológica, psíquica y social. (Arnold et al; 2009)

Inclusión/ Exclusión Secundaria: se entiende como la posibilidad de que los adultos mayores puedan o no acceder a redes de apoyo, las que pueden significar beneficios de reciprocidad en situaciones de exclusión primaria compartida (Robles; 2005). Mediante estas redes de apoyo los adultos mayores pueden satisfacer necesidades y compensar situaciones desventajosas. Estas redes pueden establecerse con familiares, vecinos, amigos u otros con los que puedan generar vinculaciones de tipo colaborativo (Arnold et al; 2009).

Inclusión/ Exclusión Simbólica: esta modalidad indica la producción y circulación de imaginarios o representaciones sobre los adultos mayores, que pueden ampliar o limitar sus posibilidades de exclusión e inclusión. Dentro de ellas se puede observar: producciones periodísticas, artísticas, textos de instrucción escolar y obras literarias. Además se puede encontrar con las distinciones con que se indica y describe la condición de envejecimiento, sus distintas etapas y estilos y otros aspectos que pueden influir en su discriminación positiva o negativa. (Arnold et al; 2009)

Inclusión/ Exclusión Heterorreferida: en base a lo que se ha entendido como Inclusión/ Exclusión Autorreferida en las investigaciones revisadas (Arnold et al; 2009) y como la presente investigación no consideró la propia observación de los adultos 
mayores sobre los procesos de inclusión y exclusión que los afectan, esta dimensión será entendida en la presente tesis como: las percepciones, sensaciones y expectativas sobre los adultos mayores, la vejez o el envejecimiento que poseen los demás miembros de la sociedad. Las que pueden reforzar o restringir los espacios de inclusión y exclusión de los adultos mayores.

\section{Marco metodológico}

El tipo de estudio realizado es de carácter Descriptivo correspondiente a un diseño Cualitativo. La unidad de estudio está formada por los 63 textos escolares oficiales del MINEDUC durante el año 2009.

Con el fin de develar los imaginarios sociales presentes en los textos escolares oficiales del MINEDUC, se realizó un análisis de contenido cualitativo de los mismos textos. Se debe precisar que el análisis de contenido realizado se basó y estuvo guiado por el modelo operativo definido por Juan Luis Pintos (2000) para el estudio de los Imaginarios Sociales:

\section{Etapas Metodológicas:}

\begin{tabular}{|l|l|}
\hline $\begin{array}{l}\text { Primera etapa: } \\
\text { Establecimiento de la evidencia }\end{array}$ & Descripción \\
\hline $\begin{array}{l}\text { 1. Revisión de los } 63 \text { textos } \\
\text { escolares (nivel Escrito y nivel } \\
\text { Ilustraciones) }\end{array}$ & $\begin{array}{l}\text { Revisión de los } 63 \text { textos escolares utilizados por el MINEDUC } \\
\text { durante el año 2009. De acuerdo a los objetivos de la investigación, } \\
\text { esta primera revisión identificó conceptos y temáticas utilizadas y } \\
\text { relacionadas a la vejez y el envejecimiento. }\end{array}$ \\
\hline 2. Revisión a nivel de Escrito & $\begin{array}{l}\text { Análisis de contenido de las lecturas, párrafos, etc., presentes en los } \\
\text { textos del sector de Lenguaje y Comunicación de Primero Básico a } \\
\text { Cuarto Medio. Este análisis se realizó con el apoyo del programa de } \\
\text { análisis cualitativo Atlas. Ti }\end{array}$ \\
\hline $\begin{array}{l}\text { 3. Revisión a nivel de } \\
\text { Ilustraciones: }\end{array}$ & $\begin{array}{l}\text { Revisión de las Ilustraciones asociadas a la vejez y el } \\
\text { envejecimiento. Por medio de una matriz de análisis construida de } \\
\text { acuerdo a lo planteado por Javier Marzal. }\end{array}$ \\
\hline $\begin{array}{l}\text { Segunda etapa: } \\
\text { Construcción de diccionarios, } \\
\text { campos semánticos y relevancias } \\
\text { y opacidades: }\end{array}$ & $\begin{array}{l}\text { Construcción de diccionarios de los conceptos identificados en la } \\
\text { etapa de establecimiento de la evidencia (observación de primer } \\
\text { orden) } \\
\text { Construcción de campos semánticos (observación segundo orden) } \\
\text { Construcción de diferencias: relevancias/opacidades. }\end{array}$ \\
\hline
\end{tabular}

Tabla No 1: Resumen Etapas Metodológicas.

\section{Resultados}

\section{La vejez y el envejecimiento a nivel escrito}

\section{Conceptos, temáticas generales y sectores de aprendizaje}

Los conceptos, temáticas asociadas a la vejez y el envejecimiento identificadas en esta etapa y los sectores de aprendizaje en los que aparecen se muestran en el siguiente cuadro resumen.

\begin{tabular}{|l|l|l|}
\hline CONCEPTOS & TEMÁTICAS & SECTORES \\
\hline Vejez & $\begin{array}{l}\text { etapa del ciclo vital, relacionada a } \\
\text { cambios biológicos }\end{array}$ & $\begin{array}{l}\text { Ciencias Naturales, Biología, Física, } \\
\text { Química }\end{array}$ \\
\hline
\end{tabular}




\begin{tabular}{|l|l|l|}
\hline CONCEPTOS & TEMÁTICAS & SECTORES \\
\hline $\begin{array}{l}\text { Abuelo, abuela, abuelos, } \\
\text { abuelitos, (tatarabuela, } \\
\text { bisabuelo, tío abuelo, } \\
\begin{array}{l}\text { Granparents, Grandfather, } \\
\text { Grandmother, Granny) }\end{array}\end{array}$ & $\begin{array}{l}\text { Familia (árbol genealógico), formación } \\
\text { personal, orígenes familiares y } \\
\text { personales, valores, fuente de cariño, } \\
\text { conocimiento y raíces culturales } \\
\text { (mapuche) }\end{array}$ & $\begin{array}{l}\text { Pre-kinder- Kinder, Lenguaje, } \\
\text { Matemáticas, Comprensión del } \\
\text { Medio Natural, Social y Cultural, } \\
\text { Historia, geografía y ciencias } \\
\text { sociales, Inglés }\end{array}$ \\
\hline $\begin{array}{l}\text { Anciano, anciana, ancianos } \\
\text { (Old man, Old people) }\end{array}$ & $\begin{array}{l}\text { Lenguaje, Historia, geografía y } \\
\text { ciencias sociales, }\end{array}$ \\
\hline $\begin{array}{l}\text { Viejos, Viejitos, viejitas, } \\
\text { viejecillo }\end{array}$ & $\begin{array}{l}\text { asociado a la vejez, indicar presencia } \\
\text { de estereotipos (aburridos), usada } \\
\text { para plantear preguntas a los lectores }\end{array}$ & Lenguaje, Ciencias Naturales \\
\hline $\begin{array}{l}\text { Tercera edad, Adulto } \\
\text { mayor, edad avanzada, } \\
\text { Persona mayor }\end{array}$ & $\begin{array}{l}\text { referido a grupos de población, } \\
\text { aparece junto a descripción de } \\
\text { población (grupos vulnerables) }\end{array}$ & $\begin{array}{l}\text { Lenguaje, Matemáticas, Historia, } \\
\text { geografía y ciencias sociales, } \\
\text { Ciencias Naturales }\end{array}$ \\
\hline $\begin{array}{l}\text { Población pasiva, } \\
\text { jubilados, pensionados. }\end{array}$ & $\begin{array}{l}\text { Se explica los ingresos de la familia, o } \\
\text { la actividad que realizan los grupos } \\
\text { dentro de la estructura social }\end{array}$ & $\begin{array}{l}\text { Historia, geografía y ciencias } \\
\text { sociales }\end{array}$ \\
\hline $\begin{array}{l}\text { Envejecer, } \\
\text { Cambios en el organismo (deterioro; } \\
\text { enfermedad de Alzheimer, } \\
\text { descalcificación), importancia de } \\
\text { alimentarse bien. }\end{array}$ & Ciencias Naturales, Biología, \\
\hline $\begin{array}{l}\text { Crecimiento demográfico, } \\
\text { envejecimiento de la } \\
\text { población, esperanza de } \\
\text { vida, mortalidad }\end{array}$ & $\begin{array}{l}\text { cantidad de años que se vive } \\
\text { actualmente (envejecimiento } \\
\text { poblacional) }\end{array}$ & $\begin{array}{l}\text { Historia, geografía y ciencias } \\
\text { sociales }\end{array}$ \\
\hline
\end{tabular}

Tabla No 2: Resumen Conceptos y temáticas presentes en los 63 textos escolares

\section{Análisis textos escolares sector Lenguaje y Comunicación}

Posteriormente se desarrolló un análisis de contenido de las lecturas identificadas en el sector de Lenguaje y Comunicación, con el fin de ahondar en los roles, funciones, posiciones sociales, tipos de actividades, percepciones asociadas a los adultos mayores. Esta profundización se realizó con el apoyo del software cualitativo Atlas. ti. Programa que permitió segmentar los relatos en códigos representativos, los que se unificaron en dimensiones mayores llamadas familias. Las familias identificadas a través del análisis descrito, se detallan a continuación:

Mundo Tradicional: Los abuelos constituyen la base del árbol genealógico, encarnando a los antepasados familiares; esta posición daría forma a la unidad familiar, otorgándoles una identidad propia, proveyéndolos de un "sello" que permitiría el reconocimiento de cada uno de sus miembros. De esta manera los abuelos aparecen como fuente de las tradiciones distintivas de una familia

Un segundo elemento asociado a esta familia, es la gran cantidad de historias y recuerdos que los abuelos guardan sobre sus familias o tiempos pasados. Estas historias al provenir de un tiempo lejano, generan gran interés en sus nietos estimulando sus gustos personales e inclusive determinando sus vidas en algunos, como algunos escritores famosos que atribuyen a sus abuelos su gusto por la literatura, al narrarles ellos diferentes historias.

Finalmente, los abuelos dominarían un tipo de conocimiento antiguo como el uso de hierbas medicinales y la sanación de heridas.

De este modo, se puede observar que, los adultos mayores son los responsables de la mantención de las tradiciones familiares o sociales, constituyendo los estandartes de una cultura y por tanto, estableciendo y personificando las reglas y limites sociales. Cumpliendo la función de fijar los márgenes en los que las nuevas generaciones 
pueden desenvolverse, a fin de conservar la tradición y la cultura. Al mismo tiempo, la experiencia y el conocimiento acumulado durante la vida, les permite a los viejos guiar a las generaciones más jóvenes, puesto que pueden leer las señales que avecinan momentos críticos, dándoles tiempo para enfrentarlos y de ese modo alumbrar el camino a recorrer por los más jóvenes.

Características de la vejez: Esta familia agrupa a todos los códigos identificados que configuran lo que se entiende como la "Caricaturización de la vejez", es decir, los elementos por medio de los cuales se construye la vejez en los escritos. En esta construcción se observan tres planos diferentes: por un lado está lo que refiere a las características físicas de la vejez denominado "Fenotipos en la vejez", El primer rasgo identificado es la posesión de "canas", la tenencia del pelo blanco sería una particularidad de las personas de edad avanzada, la alusión a las canas o al pelo blanco se utiliza para identificar y diferenciar a los adultos mayores con respecto a otros personajes de los cuentos. Este tipo de aspectos son utilizados en las narraciones como adjetivos calificativos, con el fin de personificar a los diferentes actores que en ellos interactúan. En segunda instancia las características psicológicas de los adultos mayores identificadas como "Formas de ser en la vejez", la principal forma de ser de las personas mayores, aun cuando aparezcan en roles de abuelos, ancianos o viejos es su sabiduría. La sabiduría se manifiesta en diferentes planos; primero se observa como un elemento que permite aprovechar mejor las oportunidades presentadas en la vida. Otra forma de expresión de la sabiduría, es la capacidad que tienen de identificar problemas y de rastrear sus causas. Una tercera forma de manifestación de la sabiduría en los viejos, es el poder que tienen para reconocer aspectos positivos en personas más jóvenes. Existen otras formas de ser en la vejez (ya sea cuando aparecen como viejos, ancianos o abuelos) que se pueden clasificar como características positivas y negativas. Dentro de las positivas, en los relatos seleccionados del sector Lenguaje a través de los diferentes niveles educativos, se puede observar las siguientes: los viejos ofrecen la ayuda necesaria en momentos difíciles, por medio de sus consejos, a su vez son dulces, pacientes, bondadosos, alegres y con gran fortaleza interna. En contraposición, aparecen como neuróticos, hoscos, temerosos, tristes, desagradables y muy apegados a las reglas sociales.

Finalmente los aspectos sociales presentes en la construcción de los viejos designado con el nombre de "Aspectos sociales en la vejez". Esta dimensión tiene como elemento común la indicación de roles o funciones y estatus o posición ocupada por los adultos mayores o atribuida por terceros presentes en la vejez. Los relatos muestran, como ciertos comportamientos esperados, por quienes rodean a los adultos mayores, se transforman en expectativas sociales que, finalmente, dan forma a un modelo de comportamiento a seguir por ellos, en donde hay situaciones y una forma de proceder que no sería adecuado de realizar en la vejez; sino que pertenecen a otras edades

Dentro de la posición social ocupada por los adultos mayores, se evidencia una presencia de la exclusión de las personas mayores de algunos ambientes sociales. Esto sería consecuencia de los efectos degenerativos del proceso de envejecimiento, como algunos accidentes vasculares o de otro tipo que impiden que las personas hablen o producen que se vayan ensimismando; lo anterior tendría como resultado que las personas dejaran de interactuar con los demás, ya sea niños, jóvenes o adultos. Esta falta de de comunicación con los demás acarrearía que se les relegara y aislara de a poco de las dinámicas familiares y sociales. 
Dentro de los Aspectos sociales en la vejez, se puede observar, la presencia de la vulnerabilidad asociada a aspectos sociales, es decir como una condición social que ubica a los adultos mayores en el entramado social.

Relaciones sociales: En los relatos del sector de Lenguaje y Comunicación se observan relaciones sociales mantenidas por los adultos mayores con otras generaciones, entre ellas destaca las que establecen principalmente con los niños, este vínculo se expresa en la relación abuelo/nietos; apareciendo como una constante en los relatos de los textos de este sector de aprendizaje. Esta cercana interacción, se caracteriza por una preocupación reciproca, si bien los abuelos cuidan, protegen y enseñan a sus nietos, ellos por su parte los acompañan y entregan cariño. Generalmente los factores que impiden o dificultan dicho vínculo, son los efectos degenerativos propios del proceso de envejecimiento, muchas veces las formas de enfrentar estos efectos, por parte de la familia, impiden que los nietos se les acerquen o compartan con ellos.

En menor medida se puede observar las relaciones de género entre adultos mayores y sus pares, en algunos párrafos presentes en algunos escritos de Lenguaje se observan los espacios que cada género ocupa al interior de la familia. En ellos se advierte que el lugar de las mujeres adultas mayores es el dominio de los aspectos domésticos, como la preparación de los alimentos, cuando eso sucede los hombres las observan y respetan lo que hacen.

Envejecer: Esta dimensión alude al tema relacionado con el proceso de envejecimiento, principalmente se asocia a la presencia de problemas médicos y de salud que van surgiendo a medida que avanza la edad de un individuo. Este envejecimiento biológico es acompañado por la percepción de un envejecimiento social, entendido como la aparición de malas experiencias y situaciones que hacen a las personas envejecer más rápido.

Otro tema presente en el envejecimiento, es la tensión sostenida entre juventud y vejez. En los escritos se observa como las personas mayores no quieren llegar a viejos, anhelando con fuerza la juventud, buscando formulas para volver a ella. Es así como la juventud es un bien deseado y se presenta como un evidente beneficio frente a la vejez. Esto se explica por la percepción que la vejez haría perder la salud y el vigor de otros tiempos. En el caso de las mujeres la vejez hace perder la belleza y se presenta como un elemento que amenaza su forma de vida. En base a lo expuesto, se observa como en las comunicaciones presentes en el sistema social, la juventud aparece como un bien deseado por todos, no sólo por quienes han llegado a la etapa de la vejez, sino también por quienes se encuentran en la niñez, de esta manera tanto niños como viejos codician la juventud. La vejez es vista como un sino trágico.

Estereotipos sociales: Esta última dimensión está formada por las alusiones explicitas a los estereotipos sociales. Por otro lado esta dimensión reúne la identificación de lenguaje estereotipado en algunos escritos de los textos de Lenguaje.

En el texto de Lenguaje de 40 medio se trata la presencia de estereotipos a nivel social, nombrándolos y explicándolos a los alumnos. Uno de ellos sería el estereotipo por edad; el cual significa "atribuir a ciertos grupos etarios características inmutables, basadas en prejuicios, como por ejemplo que los jóvenes son irresponsables, que los niños son molestos y que los viejos son molestos". 
El segundo grupo, corresponde al uso de lenguaje estereotipado, presente en el desarrollo de algunas lecturas, tales como:

- $\quad$ ivieja de los diablos!: se utiliza para enfatizar que la persona, en este caso una adulta mayor, ha provocado problemas a un grupo de personas determinadas.

- $\quad$ iviejo verde!: usado para destacar que el hombre esta realizando acciones que no van de acuerdo con su edad, como mirar y encontrar bonitas a mujeres mucho más jóvenes que él.

- $\quad$ iBandida, tu abuela!: aparece en frases que constituyen respuestas de un personaje, con el fin de liberarse u objetar algún tipo de imputación que se le hace.

\section{La vejez y el envejecimiento a nivel ilustración}

A continuación se mostrarán los resultados encontrados a nivel de ilustraciones en los 63 textos escolares revisados. Primero se detalla la presencia de ilustraciones de acuerdo a la frecuencia de aparición por tamaño. Posteriormente, se presentan los temas expresados asociados a la vejez y el envejecimiento por medio de las ilustraciones

\section{Aparición de Ilustraciones por tamaño y frecuencia}

De acuerdo a lo planteado por Pintos (2003), para el análisis de las ilustraciones identificadas en los textos escolares se utilizaron dos criterios que permitieron su clasificación y posterior interpretación, por un lado el tamaño mostrado en la hoja y por otro lado la frecuencia de aparición de las ilustraciones por tamaño. Tanto el tamaño como la frecuencia permiten establecer el lugar ocupado por las ilustraciones al interior de los textos, posibilitando la asignación del nivel de importancia de los temas que comunican.

Por tal motivo se definieron cuatro tipos de tamaño a reconocer en las ilustraciones presentes en los textos, los cuales son:

- $\quad$ "Menos de un cuarto de hoja": S

- $\quad$ "Un cuarto de hoja": M

- $\quad$ "Mitad de hoja": L

- $\quad$ "Una plana o más": XL

El total y la distribución de ilustraciones asociadas a la vejez y el envejecimiento por tamaño en los 63 textos, se muestran en la siguiente tabla:

\begin{tabular}{|l|l|l|l|}
\hline 63 TEXTOS & Tamaño Ilustración & Frecuencia & Total \\
\cline { 2 - 3 } & Menos de un cuarto de hoja (S) & 56 & \multirow{2}{*}{238} \\
\cline { 2 - 3 } & Un cuarto de hoja (M) & 132 \\
\cline { 2 - 3 } & Mitad de hoja (L) & 23 \\
\cline { 2 - 3 } & Una plana o más (XL) & 27 & \\
\hline
\end{tabular}

Tabla No 3: Distribución Tamaño Ilustraciones presentes en los 63 textos.

Teniendo presente la estructura de los textos escolares, formado por unidades que se dividen en tres partes; Inicio de la unidad, Desarrollo de la Unidad y Cierre de la Unidad, podemos decir que las ilustraciones de tamaño "Menos de un cuarto de hoja" y 
"Un cuarto de hoja" se ubican generalmente en lo que constituye el Desarrollo de la Unidad, utilizándose frecuentemente como un apoyo al desarrollo del contenido, ejemplificando o ilustrando los diferentes temas tratados por la unidad o insertándose dentro de los temas complementarios a la unidad, como es el caso de; "para discutir", "no olvides que", "dato interesante", "ayuda de memoria", "personajes de la ciencia", ejercicios de aplicación como usos gramaticales, vocabulario, ejercicios matemáticos, etc.

Por su parte los tamaños "Mitad de Hoja" y "Una plana o más" se utilizan para motivar actividades o introducir las unidades, generalmente constituyen espacios en donde se muestra una situación y después se invita a los estudiantes a reflexionar sobre lo observado en ellas. Cabe destacar que la presencia de algún rasgo asociado a la vejez y el envejecimiento en dichas ilustraciones sólo se presenta como parte del "paisaje" de la imagen, por lo que el tema no constituye un fin en si mismo. Las únicas ilustraciones de estos tamaños, que relacionan de forma más directa, a la vejez y el envejecimiento, son las unidades que versan sobre la familia o las que tratan sobre el crecimiento demográfico y sus consecuencias.

\section{Temas presentes en las ilustraciones}

Continuando con la respuesta al primer objetivo específico planteado para esta investigación, se procederá describir las temáticas asociadas a la vejez y el envejecimiento interpretadas a nivel de ilustraciones.

Fenotipo de los adultos mayores: Aparece principalmente en las ilustraciones que constituyen dibujos, configurando una especie de caricatura de lo que son las personas que han llegado a la etapa de la vejez. En este sentido los elementos que los representan son; el pelo blanco recogido en un tomate en el caso de las mujeres y la presencia de calvicie, bigotes y barba en el caso de los hombres. Se les presenta utilizando accesorios como: anteojos, bastón, guantes, vestimenta de colores oscuros. Se les muestra encorvados y con dificultades para desplazarse por lo que en general permanecen sentados.

Ubicación de los adultos mayores: La ubicación de los adultos mayores en las ilustraciones, ya sea hombres o mujeres, depende de si se encuentran en compañía o solos. Cuando aparecen en compañía, en general lo hacen dentro de la familia, compartiendo con ellos una comida, una salida al parque, o aparecen junto a sus nietos, cocinándoles ricos postres, cuidándolos, ayudándolos. En el caso que los adultos mayores aparezcan solos; se ubican en un sector periférico de la acción, generalmente sentados como espectadores de lo que sucede en ella.

Abuelos/as: La figura de los abuelos/as aparece en las ilustraciones, ya sea como fotografía o dibujo (caricatura, pintura), en ellas se observa una imagen que tiende a ser amable y cariñosa ya que con frecuencia son ilustrados junto a sus nietos, abrazándolos o recibiendo sus besos, sonriendo, con niños sentados en sus rodillas, compartiendo su tiempo con él. La figura de los abuelos es utilizada en las unidades que tratan sobre la familia como un indicador de un tipo de familia especial, diferente de la nuclear. Se les utilizada para ilustrar, por un lado, familias extendidas formada por muchos miembros donde los abuelos/as son sólo un miembro más, o por otro lado familias en donde los abuelos debieron hacerse cargo de los nietos.

Relaciones intergeneracionales: Los adultos mayores aparecen relacionándose principalmente con las generaciones jóvenes, especialmente con sus nietos/as, los que 
en su mayoría son niños/as, aun cuando aparecen interactuando con adolescentes, es mucho más común verlos asociados a los primeros. Esto es así porque se les grafica en contextos familiares, en donde están a cargo o apoyan el cuidado de los niños. La relación con los niños aparece como algo más natural, impregnada de cariño y una mutua necesidad de acercarse y realizar actividades en conjunto, ambos aparecen retratados felices cuando están juntos. La relación con los adolescentes no se presenta tan clara en las ilustraciones, sino que oscila entre momentos felices y de entendimiento mutuo hasta situaciones en las que se observa una tensión entre ambos, generalmente producida por el choque de intereses y gustos.

Relaciones de género: En las ilustraciones, ya sea en el tipo dibujo o fotografía, es posible advertir ciertos elementos configuradores de las diferencias de género entre hombres y mujeres adultas mayores. En este sentido las ilustraciones analizadas otorgan elementos de los que se enuncia la construcción social del género, indicando qué tipo de actividades realizan las mujeres y los hombres.

Las mujeres en general aparecen en un contexto familiar desarrollando labores domésticas o tradicionalmente asociadas a lo femenino, principalmente en lo que se refiere al cuidado de los nietos. Realizando acciones como; tejer, lavar ropa, cocinar. Los hombres, por su parte, son ilustrados en acciones relacionadas con sus gustos personales y que no necesariamente tienen una consecuencia directa en el resto del grupo familiar, es por eso que aparecen; regando, jardineando, paseando las mascotas, leyendo, viendo televisión, arreglando el automóvil o desarrollando algún tipo de actividad laboral, como es atender o ser dueño de un puesto de verduras en la feria.

Vulnerabilidad: Otro tema presente en las ilustraciones, ya sean de tipo fotografía o dibujo, es la vulnerabilidad asociada a las personas mayores. Esto es así porque muchas de las ilustraciones los ilustran tranquilos y quietos ya sea sentados en un parque o sentados en sus casas realizando actividades que no les significa movimiento y por tanto se encuentren fuera algún tipo de riesgo, como por ejemplo ver televisión, tejer, etc. Cuando aparecen realizando actividades o movimientos físicos, éstos deben ser asistidos por un tercero o por un bastón que les facilita el movimiento alejándolos de situaciones riesgosas.

Situación de abandono y soledad: Algunas de las ilustraciones identificadas en las unidades de los textos escolares de los diferentes niveles educacionales, transmiten la situación de abandono y soledad en la que vivirían las personas de edad avanzada. En ellas se ilustran solos y abandonados y se les presenta como no dueños de su destino sino que a merced de las consecuencias que los comportamientos y acciones de terceros les puedan acarrear; en este sentido los adultos mayores se ilustran como personas sin autonomía.

Conocimiento y éxito en la vejez: Un tema que se vincula a la vejez en los textos escolares es la alta presencia de fotografías, retratos, pinturas o dibujos de personas de renombre mostrados en la etapa de vejez y que a lo largo de diferentes periodos históricos, contribuyeron en diferentes áreas o disciplinas tales como; matemáticos, químicos, biólogos, inventores, navegantes, conquistadores, escritores y poetas, personas que promovieron la paz mundial como santos o personas de fe, personajes provenientes del mundo político como presidentes, pensadores sociales o miembros de la iglesia, como papas, sacerdotes, etc. En estas ilustraciones, se puede advertir la relación producida entre el éxito en las actividades desarrolladas durante la vida y la 
vejez. Al parecer el éxito y el reconocimiento social de las actividades profesionales, laborales, o en lo que hayamos decidido dedicar nuestras energías están mediados por esfuerzos sistemáticos y continuados que se evidencian en la etapa de la vejez.

Asociado a lo anterior también se encuentra en los textos escolares, la presencia de los magos, los que son retratados, dibujados o fotografiados en la etapa de vejez con barbas largas y blancas. Nuevamente surge la importante relación entre la etapa de la vejez y el alto nivel de conocimiento especializado. En el caso de los magos sería una sapiencia especial, secreta que despierta el interés de los demás y que a su vez es altamente necesitada como guía, frente a las adversidades de la vida.

Buen comportamiento ciudadano: Algunas ilustraciones de tipo fotografía y dibujo muestran a los adultos mayores exhibiendo un buen comportamiento ciudadano, ya sea porque aparecen en las filas de votación, ejerciendo su deber cívico o porque se les muestra realizando acciones responsables con el medio ambiente como botar la basura en los espacios habilitados para ello o promoviendo el reciclaje de algunos materiales.

Tecnología: La tecnología aparece como un tema nuevo y distante para los adultos mayores, con el cual de a poco han empezado a familiarizarse. En las ilustraciones que tratan este tema se ve que los adultos mayores deben aprender este conocimiento, el cual se les hace difícil de comprender principalmente por la cantidad de conceptos que desconocen. Quienes les enseñan siempre son personas más jóvenes, ya sea sus mismos nietos o profesores de edad adulta.

Trabajo: Prácticamente ninguna imagen trata el tema laboral relacionado con los adultos mayores; en general se les presenta realizando labores domésticas o de goce personal.

Sólo se identificó una imagen de tipo fotografía que se refiere a este tema, la cual se inserta en una actividad del sector de Inglés de Primero Medio. En ella se muestra una serie de personas vestidas de forma formal e informal, sólo una de ellas corresponde a un adulto mayor. En la actividad se les pide a los niños que elijan, de las ilustraciones presentes cuales son las que corresponderían a la mejor forma de vestirse para enfrentar una entrevista de trabajo.

Vejez y cultura mapuche: Un tema que aparece reflejado en las ilustraciones analizadas en los diferentes niveles escolares, es la relación que surge entre vejez y cultura mapuche. En muchas ilustraciones se utiliza miembros de este grupo étnico para representar la composición de la sociedad chilena, identificando sus diferencias al interior. Pese a que ese es el objetivo que se persigue, las personas mapuches que aparecen en las fotografías generalmente pueden considerarse como personas que se encuentran en la etapa de la vejez. Por otro lado, también son utilizadas para escenificar ilustraciones de narraciones o cuentos, en donde se les representa como abuelos que cuidan a sus nietos. Esta relación podría explicarse por la implícita relación que existiría entre vejez, abuelos y el mundo tradicional y rural.

Envejecimiento: En las ilustraciones identificadas en los textos escolares de los diferentes niveles se encuentran algunas que se relacionan al proceso de envejecimiento; principalmente aparecen junto a los temas que tratan sobre el crecimiento demográfico y las necesidades y desafíos que impone, como mayor cuidado en la salud, como la importancia de vacunarse, o los cambios que se van produciendo en el metabolismo al envejecer como alimentarse en menor cantidad que los jóvenes. 


\section{Imaginarios sociales de la vejez y el envejecimiento}

Habiendo cumplido el primer paso del modelo de Pintos ya descrito, referido al establecimiento de la evidencia, se procederá con las siguientes etapas que componen el modelo, es decir, la construcción de diccionarios con los cuales poder definir los campos semánticos, para distinguir las relevancias y opacidades que forman los Imaginarios de la vejez y el envejecimiento en los textos escolares del MINEDUC.

Cabe precisar que la construcción de los campos semánticos, basados en los diccionarios, se hará de acuerdo al enfoque teórico que guía la investigación, a fin de responder los objetivos planteados para esta investigación, relacionados con el enfoque de Inclusión/Exclusión. Como se observó se definieron cuatro formas de expresión de la Inclusión/Exclusión, las que son:

- Inclusión/Exclusión Primaria

- Inclusión/Exclusión Secundaria

- Inclusión/Exclusión Simbólica

- Inclusión/Exclusión Heterorreferida

Si bien se puede considerar que el material empírico utilizado se inserta dentro de la Inclusión/ Exclusión Simbólica y Hetorreferida, ya que corresponde a los textos escolares del sistema educativo chileno; material empírico que comunica las observaciones sobre los fenómenos sociales (en este caso la vejez y el envejecimiento) que construye la sociedad que los alberga, tanto a nivel de indicaciones generales como de percepciones de terceros sobre un grupo determinado de la población (en este caso los adultos mayores) se pudieron distinguir en su interior la aparición de las cuatro dimensiones en las que se expresa el fenómeno de la Inclusión/ Exclusión señalado.

\section{Construcción de diccionarios y campos semánticos}

Sobre la base del análisis de contenido desarrollado, se construyeron los diccionarios, distinguiendo en función del nivel de aparición de las temáticas y conceptos asociados a la vejez y en el envejecimiento: ya sea a nivel Escrito, en los 63 textos escolares, a nivel de análisis de contenido en los relatos del sector de Lenguaje y Comunicación y a nivel de análisis de las ilustraciones reconocidas en los 63 textos escolares. Cabe precisar que la atribución de los diccionarios a los campos semánticos definidos, se realizó en función de la forma de aparición de los diccionarios, es decir, si se presentaban de forma Inclusiva o Exclusiva.

\section{Nivel escrito (63 textos)}

Según lo planteado, para este nivel, el diccionario quedo establecido con las siguientes apariciones de temas asociados a la vejez y el envejecimiento y su correspondiente campo semántico.

\begin{tabular}{|l|l|l|l|l|l|}
\hline $\begin{array}{l}\text { Diccionario: } \\
\text { Palabras }\end{array}$ & Frecuencia & Agrupación & $\begin{array}{l}\text { Total } \\
\text { Agrupación }\end{array}$ & $\begin{array}{l}\text { Campo } \\
\text { semántico }\end{array}$ & $\begin{array}{l}\text { Total Campo } \\
\text { Semántico }\end{array}$ \\
\hline Abuelo/a & 64 & $\begin{array}{l}\text { Ámbito } \\
\text { Familiar }\end{array}$ & 275 & $\begin{array}{l}\text { Inclusión } \\
\text { Secundaria }\end{array}$ & 345 \\
\hline $\begin{array}{l}\text { Grandfather/grandm } \\
\text { other }\end{array}$ & 7 & & & \\
\hline
\end{tabular}




\begin{tabular}{|c|c|c|c|c|c|}
\hline $\begin{array}{l}\text { Diccionario: } \\
\text { Palabras }\end{array}$ & Frecuencia & Agrupación & $\begin{array}{l}\text { Total } \\
\text { Agrupación }\end{array}$ & $\begin{array}{l}\text { Campo } \\
\text { semántico }\end{array}$ & $\begin{array}{l}\text { Total Campo } \\
\text { Semántico }\end{array}$ \\
\hline Abuelos & 59 & & & & \\
\hline Grandparents & 48 & & & & \\
\hline Abuelitos & 6 & & & & \\
\hline Granpa & 28 & & & & \\
\hline Grandma & 43 & & & & \\
\hline Granny & 4 & & & & \\
\hline Granddad & 2 & & & & \\
\hline $\begin{array}{l}\text { Tatarabuelo, } \\
\text { bisabuelo, tío abuelo }\end{array}$ & 14 & & & & \\
\hline Anciano/a & 70 & $\begin{array}{l}\text { Ámbito } \\
\text { Comunitario }\end{array}$ & 70 & & \\
\hline Jubilado & 2 & \multirow{4}{*}{$\begin{array}{l}\text { Sistema } \\
\text { Económico }\end{array}$} & \multirow[t]{4}{*}{19} & \multirow{9}{*}{$\begin{array}{l}\text { Inclusión } \\
\text { Primaria }\end{array}$} & \multirow[t]{9}{*}{263} \\
\hline Jubilados & 5 & & & & \\
\hline $\begin{array}{l}\text { Pensión } \\
\text { (pensionados) }\end{array}$ & 10 & & & & \\
\hline Población pasiva & 2 & & & & \\
\hline Ancianos & 48 & \multirow{5}{*}{$\begin{array}{l}\text { Clasificación } \\
\text { Social: } \\
\text { Políticas } \\
\text { Públicas, } \\
\text { consumidores }\end{array}$} & \multirow[t]{5}{*}{244} & & \\
\hline $\begin{array}{l}\text { Adulto/a mayor } \\
\text { (población) }\end{array}$ & 11 & & & & \\
\hline Adultos mayores & 19 & & & & \\
\hline Tercera edad & 12 & & & & \\
\hline Viejo/a & 154 & & & & \\
\hline Viejito/Viejita & 8 & \multirow{5}{*}{$\begin{array}{l}\text { Clasificación } \\
\text { Social }\end{array}$} & \multirow[t]{5}{*}{44} & \multirow{10}{*}{$\begin{array}{l}\text { Inclusión } \\
\text { Simbólica }\end{array}$} & \multirow[t]{10}{*}{145} \\
\hline Viejecillo/viejecilla & 6 & & & & \\
\hline Viejos & 20 & & & & \\
\hline Edad avanzada & 3 & & & & \\
\hline Persona mayor & 7 & & & & \\
\hline $\begin{array}{l}\text { Crecimiento } \\
\text { demográfico }\end{array}$ & 11 & \multirow{3}{*}{$\begin{array}{l}\text { Envejecimient } \\
\text { o } \\
\text { Demográfico }\end{array}$} & \multirow[t]{3}{*}{67} & & \\
\hline $\begin{array}{l}\text { Envejecimiento de la } \\
\text { población }\end{array}$ & 11 & & & & \\
\hline Esperanza de vida & 45 & & & & \\
\hline Envejecer & 2 & \multirow{2}{*}{$\begin{array}{l}\text { Envejecimient } \\
\text { o biológico }\end{array}$} & \multirow[t]{2}{*}{34} & & \\
\hline Vejez & 32 & & & & \\
\hline Viejo/a & 35 & $\begin{array}{l}\text { Caracterizació } \\
\text { n de la vejez }\end{array}$ & 35 & $\begin{array}{l}\text { Inclusión } \\
\text { Heterorrefer } \\
\text { ida }\end{array}$ & 35 \\
\hline
\end{tabular}

Tabla No 4: Construcción Campos Semánticos Nivel Escrito

De acuerdo a la tabla anterior, en donde se presentan los conceptos identificados asociados a la vejez y el envejecimiento agrupados y relacionados con los campos semánticos definidos (tipos de Inclusión/Exclusión), es necesario clarificar que el proceso de agrupación de los conceptos se hizo en directa relación al contexto en el cual aparecen en los textos escritos.

En este sentido se definió el Ámbito Familiar para agrupar los conceptos asociados al "abuelazgo" (abuelos/as, grandparents, tatarabuelos, bisabuelos, etc.). El Ámbito Comunitario fue utilizado para agrupar la aparición del concepto anciano/a, se definió así para destacar que cuando un anciano/a aparece en los textos escolares, se le

Revista Mad. No 22, Mayo de 2010. Departamento de Antropología. Universidad de Chile http://www.revistamad.uchile.cl/22/Jorquera_07.pdf 
otorga una función social específica. Por las razones expuestas, ambas agrupaciones se consideran como ámbitos de Inclusión de los adultos mayores presentes en los textos escolares, Inclusión de tipo Secundaria, ya que refiere al mundo de las relaciones sociales.

Con respecto a los conceptos de jubilados, pensionados y población pasiva, se consideró que apuntan al lugar ocupado por los adultos mayores dentro del Sistema Económico. Mientras que los conceptos de adulto/a mayor, adultos mayores, tercera edad, viejo/a, se utilizan para la Clasificación de la población pero con el fin de mostrarlos como población objeto de las Políticas Públicas o como un Grupo de Consumo diferenciado y especifico, es decir, orientados hacia su inclusión en los sistemas funcionales formales de la sociedad. Por tal motivo ambas agrupaciones se consideraron como ámbitos de Inclusión de los adultos mayores presentes en los textos escolares, Inclusión de tipo Primaria, puesto que tiene como referente los sistemas funcionales formales de la sociedad.

La presencia de los conceptos viejecillo/a, viejos, edad avanzada, y persona mayor aparecen en los textos escolares sólo como forma de indicar a los adultos mayores, es decir, estos conceptos son usados sólo para nombrarlos o referirse a ellos, por eso se les agrupó como Clasificación Social. Del mismo modo los conceptos de Crecimiento demográfico, Envejecimiento de la población y Esperanza de vida, indican el Envejecimiento demográfico. Finalmente la aparición de los conceptos de Envejecer y Vejez se agruparon como Envejecimiento Biológico ya que se usan para indicar el proceso biológico que implica envejecer. De este modo, las tres agrupaciones fueron entendidas como ámbitos de Inclusión de los adultos mayores identificados en los textos escolares, Inclusión de tipo Simbólica, ya que sólo aparecen para nombrar, indicar o referirse a ellos, sin ninguna función asociada.

Por último en el análisis de los textos escolares a nivel de los escritos, es posible advertir, nuevamente, el concepto de viejo/a, pero utilizado en relación a la caracterización de algunos personajes o personas importantes. Por lo que se agrupó bajo el nombre de Caracterización de la vejez. De tal forma se entendió como un ámbito de inclusión de la vejez, Inclusión de tipo Heterorreferida puesto que apunta a la percepción por parte de terceros.

\section{Nivel escritos sector lenguaje y comunicación}

En vista de que el análisis de contenido realizado en los textos escolares del sector Lenguaje y Comunicación responde a un nivel lógico diferente, puesto que no refiere a la aparición de conceptos explícitos en los textos escolares, si no que a la identificación de temas presentes producto de una observación de segundo orden por parte de la investigadora. Se consideró pertinente construir de forma diferente los diccionarios presentes en ellos para su posterior vinculación con los campos semánticos definidos para esta investigación. De esta manera el diccionario, para los textos del sector Lenguaje y Comunicación, se definió en base a los códigos identificados en el análisis de contenido (realizado en el software de análisis cualitativo Atlas. ti), constituyéndose con las siguientes apariciones de temas asociados a la vejez y el envejecimiento y su correspondiente campo semántico. 


\begin{tabular}{|c|c|c|c|c|c|}
\hline $\begin{array}{l}\text { Diccionarios: } \\
\text { códigos }\end{array}$ & Frecuencia & Agrupación & $\begin{array}{l}\text { Total } \\
\text { Agrupación }\end{array}$ & $\begin{array}{l}\text { Campos } \\
\text { Semánticos }\end{array}$ & $\begin{array}{l}\text { Total } \\
\text { Campos } \\
\text { Semánticos }\end{array}$ \\
\hline $\begin{array}{l}\text { Orígenes/ } \\
\text { antepasados/ } \\
\text { recuerdos }\end{array}$ & 47 & Mundo Tradicional & 47 & \multirow[t]{3}{*}{$\begin{array}{l}\text { Inclusión } \\
\text { Secundaria }\end{array}$} & \multirow[t]{3}{*}{63} \\
\hline $\begin{array}{l}\text { Relaciones } \\
\text { Intergeneracionales }\end{array}$ & 14 & \multirow[t]{2}{*}{ Relaciones sociales } & \multirow[t]{2}{*}{16} & & \\
\hline Relaciones de género & 2 & & & & \\
\hline Aspectos Biológicos & 4 & $\begin{array}{l}\text { Envejecimiento } \\
\text { Biológico }\end{array}$ & 4 & $\begin{array}{l}\text { Inclusión } \\
\text { Heterorreferida }\end{array}$ & 65 \\
\hline Juventud/Vejez & 14 & \multirow{2}{*}{$\begin{array}{l}\text { Envejecimiento } \\
\text { Social }\end{array}$} & \multirow[t]{2}{*}{16} & & \\
\hline Social & 2 & & & & \\
\hline $\begin{array}{l}\text { Formas de ser } \\
\text { en la vejez }\end{array}$ & 17 & \multirow[t]{3}{*}{$\begin{array}{l}\text { Caricaturización } \\
\text { Vejez }\end{array}$} & \multirow[t]{3}{*}{44} & & \\
\hline Fenotipo en la vejez & & & & & \\
\hline Vulnerabilidad & 27 & & & & \\
\hline Por edad & 1 & \multirow[t]{2}{*}{ Estereotipos } & 1 & & \multirow[t]{2}{*}{3} \\
\hline $\begin{array}{l}\text { Lenguaje } \\
\text { Estereotipado }\end{array}$ & 3 & & 3 & $\begin{array}{l}\text { Exclusión } \\
\text { Heterorreferida }\end{array}$ & \\
\hline
\end{tabular}

Tabla No 5: Construcción Campos Semánticos Nivel Escrito Sector Lenguaje y Comunicación

Al igual que en la tabla No 5 , la construcción de los diccionarios de las temáticas identificadas en los textos del sector de Lenguaje y Comunicación se definieron en relación al contexto de aparición de los temas.

En relación a lo anterior, se agrupó en la familia Mundo Tradicional los códigos referidos a orígenes/antepasados/recuerdos. Estos códigos expresan las funciones específicas que cumplen los adultos mayores al interior de una familia o grupo social. Por otro lado bajo la familia Relaciones sociales se seleccionó los códigos que muestran las relaciones que establecen los adultos mayores con otras generaciones o con sus pares en el sentido de género. Ambas agrupaciones se observaron como ámbitos de inclusión de los adultos mayores, Inclusión de tipo Secundaria, puesto que refiere a las relaciones sociales y al mundo de la interacción y redes sociales.

Con respecto a la aparición de códigos asociados a los aspectos biológicos del envejecimiento, se agruparon bajo la categoría de Envejecimiento Biológico, puesto que refieren a las descripciones o alusiones de los elementos degenerativos del envejecimiento. Por otro lado, lo que refiere a algunas características sociales que acompañarían dicho proceso, se definió como Envejecimiento Social. Los códigos que indican las caracterizaciones utilizadas en los textos del sector Lenguaje y Comunicación se agruparon bajo la dimensión Caricaturización de la vejez, puesto que muestran la forma de representar la vejez en los relatos analizados. Finalmente la presencia de indicaciones explicitas a los estereotipos por la edad se agruparon bajo la dimensión Estereotipos. Todas las familias descritas se observan como ámbitos de inclusión de los adultos mayores, Inclusión de tipo Heterorreferida ya que apunta a las percepciones o expectativas de terceros sobre los adultos mayores o la vejez.

Finalmente, la presencia de lenguaje estereotipado en algunos cuentos fueron agrupados también como Estereotipos, lo que indica un ámbito de exclusión de los adultos mayores, Exclusión de tipo Heterorreferida ya que muestra la caracterización de la vejez utilizada de forma negativa por parte de terceros. 


\section{Nivel ilustraciones (63 textos)}

Los diccionarios construidos en base a las temáticas identificadas en el análisis de las ilustraciones, y sus correspondientes campos semánticos, son los siguientes:

\begin{tabular}{|c|c|c|c|c|c|}
\hline $\begin{array}{l}\text { Diccionarios: } \\
\text { Ilustraciones }\end{array}$ & Frecuencia & Agrupación & $\begin{array}{l}\text { Total } \\
\text { Agrupación }\end{array}$ & $\begin{array}{l}\text { Campos } \\
\text { Semánticos }\end{array}$ & $\begin{array}{l}\text { Total Campos } \\
\text { Semánticos }\end{array}$ \\
\hline $\begin{array}{l}\text { Fenotipo Adultos } \\
\text { Mayores }\end{array}$ & 101 & $\begin{array}{l}\text { Caricaturización } \\
\text { vejez }\end{array}$ & 101 & $\begin{array}{l}\text { Inclusión } \\
\text { Heterorreferida }\end{array}$ & 101 \\
\hline $\begin{array}{l}\text { Envejecimiento } \\
\text { Biológico }\end{array}$ & 24 & Sistema de Salud & 24 & \multirow[t]{5}{*}{ Inclusión Primaria } & \multirow[t]{5}{*}{135} \\
\hline $\begin{array}{l}\text { Conocimiento y } \\
\text { éxito en la vejez }\end{array}$ & 98 & \multirow[t]{2}{*}{$\begin{array}{l}\text { Sabiduría } \\
\text { Legitimada }\end{array}$} & \multirow[t]{2}{*}{103} & & \\
\hline Magos & 5 & & & & \\
\hline $\begin{array}{l}\text { Buen } \\
\text { Comportamiento } \\
\text { ciudadano }\end{array}$ & 3 & Sistema Político & 3 & & \\
\hline Tecnología & 5 & Sistema Tecnológico & 5 & & \\
\hline \multirow[t]{2}{*}{ Cultura mapuche } & \multirow[t]{2}{*}{8} & $\begin{array}{l}\text { Envejecimiento } \\
\text { Demográfico }\end{array}$ & \multirow[t]{2}{*}{8} & Inclusión Simbólica & 8 \\
\hline & & Abuelos & & \multirow[t]{4}{*}{ Inclusión Secundaria } & \multirow[t]{4}{*}{65} \\
\hline $\begin{array}{l}\text { Relaciones } \\
\text { generacionales }\end{array}$ & 15 & \multirow[t]{2}{*}{ Relaciones sociales } & \multirow[t]{2}{*}{22} & & \\
\hline $\begin{array}{l}\text { Relaciones de } \\
\text { genero }\end{array}$ & 7 & & & & \\
\hline Abuelos/as & 35 & Ámbito Familiar & 35 & & \\
\hline $\begin{array}{l}\text { Adultos mayores } \\
\text { solos }\end{array}$ & 17 & \multirow[t]{2}{*}{$\begin{array}{l}\text { Condición de riesgo } \\
\text { social }\end{array}$} & \multirow[t]{2}{*}{19} & \multirow[t]{2}{*}{ Exclusión Secundaria } & \multirow[t]{2}{*}{19} \\
\hline $\begin{array}{l}\text { Abandono y } \\
\text { soledad }\end{array}$ & 2 & & & & \\
\hline \multirow[t]{2}{*}{ Vulnerabilidad } & \multirow[t]{2}{*}{15} & Sistema Económico & \multirow[t]{2}{*}{15} & \multirow[t]{3}{*}{ Exclusión Primaria } & \multirow[t]{3}{*}{18} \\
\hline & & Sistema Deportivo & & & \\
\hline Trabajo & 3 & Sistema económico & 3 & & \\
\hline
\end{tabular}

Las ilustraciones que muestran el Fenotipo en la vejez, fueron agrupadas bajo la dimensión Caricaturización de la vejez, ya que expresa las características físicas con las que se presenta la vejez. En general esta dimensión agrupa las ilustraciones de tipo dibujo presentes en los 63 textos escolares. Este tipo de temática identificada se consideró como un ámbito de inclusión, Inclusión de tipo Heterorreferida, ya que transmite la forma de representación de la vejez y los adultos mayores que tienen terceros.

Un segundo grupo de temas identificados en base al análisis de las ilustraciones presentes en los textos escolares, que permitieron construir los diccionarios, fueron los que refieren de alguna manera a los sistemas funcionales formales de la sociedad. En este sentido el Envejecimiento Biológico se agrupó bajo la dimensión Sistema de Salud puesto que su aparición en imágenes corresponde a los contenidos de la unidad que versan sobre los desafíos a nivel de salud que imponen los cambios biológicos sufridos al envejecer. Apuntando, también, hacia los sistemas funcionales formales están las ilustraciones que se asocian al Buen Comportamiento ciudadano que fueron agrupadas bajo el Sistema Político y las ilustraciones que expresan temas referidos a la 
Tecnología que se clasificaron como dentro del Sistema Tecnológico. Otro tema identificado por medio del análisis de las imágenes es que en la vejez se evidenciaría un Conocimiento exitoso, la gran cantidad de ilustraciones que componen esta temática son utilizadas, dentro de los textos, como una forma de representar o ejemplificar algún sistema funcional formal especifico: como el caso de la Ciencia, Política o Religión. Dentro de esta misma dimensión se agruparon las ilustraciones que muestran a magos, que se encontrarían entre el sistema funcional formal de la ciencia y religión. Por tal motivo, tanto las ilustraciones que expresan Conocimiento y éxito en la vejez, como los magos, se clasificaron como Sabiduría legitimada. Lo anterior se consideró que constituye un ámbito de inclusión, Inclusión de tipo Primaria, puesto que se orientan a los diferentes sistemas funcionales formales de la sociedad.

De las ilustraciones que muestran la Cultura Mapuche, se pudo observar y por tanto interpretar dos tipos de temáticas que responden a diferentes campos semánticos. Por un lado se observa la presencia de la Cultura Mapuche como una forma de ejemplificar el Envejecimiento demográfico de la población. En dicho sentido, el Envejecimiento demográfico constituiría un ámbito de inclusión del envejecimiento, Inclusión de tipo Simbólica ya que sólo constituiría una forma de nombrar, indicar y por tanto de mostrar la presencia del proceso.

Por otro lado las ilustraciones asociadas a la Cultura Mapuche, transmiten la idea de los Abuelos, ya que aparecen en contextos familiares o con niños en las piernas. Esta dimensión se asemejaría a la aparición de ilustraciones en unidades que hablan sobre la familia y que por tanto fueron tematizadas como Abuelos, esta temática se agrupó bajo la dimensión Ámbito Familiar.

Otra temática importante, y que se relaciona a las anteriores a nivel de campo semántico, son las ilustraciones que refieren a las Relaciones Generacionales y de Género que se agruparon bajo la dimensión Relaciones Sociales. La dimensión identificada como Relaciones Sociales, junto a las que agrupan al Ámbito Familiar y Abuelos, descritas, fueron consideradas como ámbitos de inclusión de la vejez, Inclusión de tipo Secundario, ya que refiere al mundo de la interacción y redes sociales en la vejez.

Finalmente se pueden observar ilustraciones que expresan temáticas que se asocian a ámbitos de exclusión de la vejez y los adultos mayores. El primer grupo de ilustraciones son las que se relacionan con temáticas de Soledad y Abandono. Estas temáticas se agruparon bajo la dimensión Condición de riesgo social, ya que expresaban la idea de que cuando los adultos mayores se encuentran solos o abandonados están propensos a sufrir accidentes o peligros. Cuando aparecen en este contexto, se consideró que representa un ámbito de exclusión, Exclusión de tipo Secundaria ya que el encontrarse solos, fundamentalmente significa que por algún motivo no se encuentran viviendo o compartiendo con su familia o pares.

Una de las ilustraciones que expresa el abandono de los adultos mayores, descrito anteriormente, a su vez enuncia otra temática relacionada a la vejez, y es la integración de las personas mayores en hogares de ancianos, de esta manera se observa como un tema relacionado a la vejez la situación de los adultos mayores institucionalizados. En este sentido, se reconoce un ámbito de Exclusión, Exclusión de tipo Primario, ya que al ingresarlos a dichos espacios les quitan toda posibilidad de vinculación con los sistemas funcionales formales. No obstante les otorgan la posibilidad de relacionarse con sus pares, lo que constituiría un ámbito de inclusión, de tipo Inclusión Secundaria. Esta imagen es ilustrativa de lo complejo del fenómeno de la 
Inclusión/Exclusión, en donde nunca se puede estar totalmente excluido de un sistema, puesto que se puede estar excluido de uno, pero incluido en otro.

También dentro de la Exclusión de tipo Primaria, se consideraron las ilustraciones que expresan Vulnerabilidad y Trabajo. La primera pudo agruparse tanto en el Sistema Deportivo (por la alusión a la actividad física) como al Sistema Económico (por su posición en la estructura social) mientras que la segunda aparece vinculada al Sistema Económico. En ambas, la posición desventajosa en la que se muestran los adultos mayores indican que se está frente a un ámbito de Exclusión de tipo Primario, ya que se les excluye de los sistemas funcionales formales mencionados.

\section{Relevancias y opacidades}

Explicado el procedimiento metodológico mediante el cual se agruparon los diccionarios en los diferentes campos semánticos, y de acuerdo a lo planteado por Pintos, proseguiremos con la ubicación de los campos semánticos identificados en él la estructura de los textos escolares, mediante la aplicación del código "relevancia/opacidad".

Es preciso señalar, que en esta etapa de aplicación del modelo operativo de los Imaginarios Sociales, lo que se intenta es volver observable la construcción que los textos escolares oficiales del MINEDUC hacen sobre la vejez y el envejecimiento. En tal sentido la frecuencia de aparición de uno de los campos semánticos no es suficiente para poder construir la relevancia y la opacidad, sino que es preciso complementar el análisis con la ubicación de las apariciones en la estructura propia del material que se analiza. De esta manera no se observa qué es lo que nos relatan los textos, sino cómo y desde dónde lo hacen (Pintos: 2007,6)

\section{Ubicación de campos semánticos a nivel Escrito (63 textos)}

De acuerdo a la estructura de los textos ya definida, los campos semánticos construidos a nivel de los escritos se ubican de la siguiente manera en la estructura del texto, es decir Inicio de la Unidad, Desarrollo de la Unidad, Cierre de la Unidad.

\begin{tabular}{|c|c|c|}
\hline Campo semántico & Frecuencia & Ubicación Texto \\
\hline Inclusión Secundaria & 345 & $\begin{array}{l}\text { Presentación de Unidad: } \\
\text { - Breve Lectura de inicio } \\
\text { Desarrollo de la Unidad: } \\
\text { - Unidades referidas a la familia } \\
\text { - Personajes de cuentos } \\
\text { - Taller: dramatización } \\
\text { - Actividades individuales } \\
\text { - Ejercicios de aplicación; } \\
\text { - ejercicios matemáticos, vocabulario, } \\
\text { - gramaticales, comprensión de lectura } \\
\text { - Desarrollo de cuentos y lecturas } \\
\text { Cierre de la unidad: } \\
\text { - auto evaluación }\end{array}$ \\
\hline Inclusión Primaria & 263 & $\begin{array}{l}\text { Desarrollo de la Unidad: } \\
\text { - Actividad inicial } \\
\text { - } \quad \text { desarrollo de contendidos de unidad } \\
\text { - Ejercicios de aplicación; ejercicios matemáticos, } \\
\text { vocabulario. }\end{array}$ \\
\hline
\end{tabular}




\begin{tabular}{|c|c|c|}
\hline Campo semántico & Frecuencia & Ubicación Texto \\
\hline $\begin{array}{l}\text { Inclusión } \\
\text { Simbólica }\end{array}$ & 145 & $\begin{array}{l}\text { Presentación de la unidad: } \\
\text { - } \quad \text { Breve lectura de inicio } \\
\text { Desarrollo de la Unidad: } \\
\text { - } \quad \text { desarrollo de contenido de unidad } \\
\text { - } \quad \text { ejercicios de aplicación matemáticos } \\
\text { personas mayores } \\
\text { - } \quad \text { Personajes de cuentos } \\
\text { - } \quad \text { Desarrollo de cuentos y lecturas } \\
\text { - } \quad \text { ejercividades grupales matemáticos } \\
\text { - } \quad \text { actividades de aprendizaje: preguntas } \\
\text { Titulo de artículo científico (único) } \\
\text { Anexos: } \\
\text { - Proyecto de investigación } \\
\text { - } \quad \text { Síntesis de la unidad } \\
\text { auto evaluación }\end{array}$ \\
\hline Inclusión Heterorreferida & 35 & $\begin{array}{l}\text { Desarrollo de la Unidad: } \\
\text { - } \quad \text { Desarrollo de cuentos y lecturas } \\
\text { - } \quad \text { Personajes de cuentos }\end{array}$ \\
\hline
\end{tabular}

Tabla No 7: Ubicación Campos Semánticos Nivel Escrito

En base a la tabla anterior, se pudo distinguir el código "relevancia/opacidad" en función de la frecuencia de aparición de los campos semánticos, más la ubicación de ellos. Realizando este cruce, el sistema de relevancia/opacidad de los escritos en los textos escolares queda constituido de la siguiente manera:

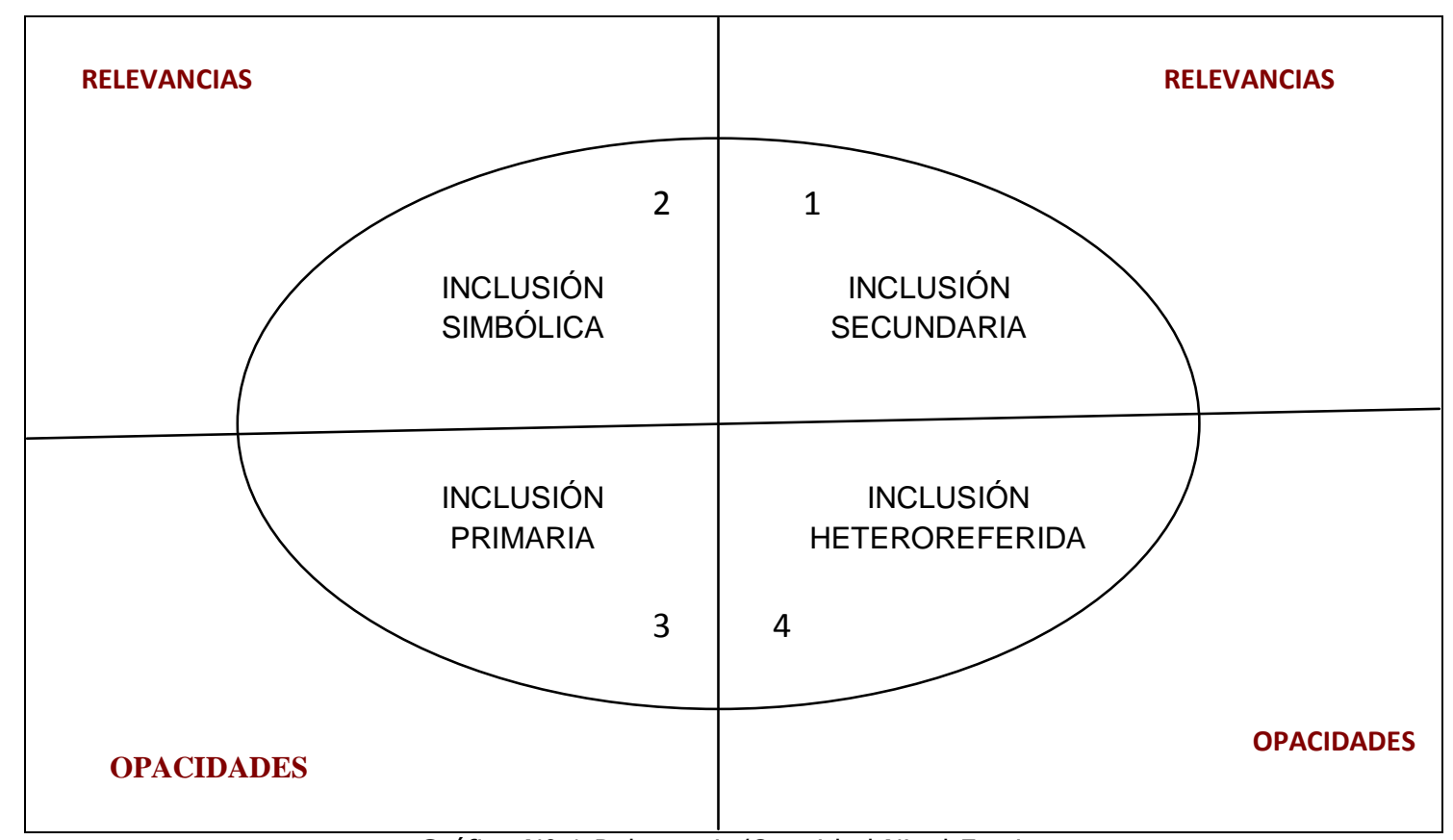

Gráfico No 1 Relevancia/Opacidad Nivel Escrito

El análisis de la frecuencia de aparición más la ubicación en la estructura del texto escolar, permite establecer que el sistema de relevancia de los escritos están dado por los campos semánticos que refieren a la Inclusión Secundaria y a la Inclusión Simbólica.

Revista Mad. No 22, Mayo de 2010. Departamento de Antropología. Universidad de Chile http://www.revistamad.uchile.cl/22/Jorquera_07.pdf 
El máximo grado de relevancia es ocupado por la Inclusión Secundaria, que tiene una frecuencia de aparición asociada a los diccionarios de 345 y se ubica en las tres partes que componen el texto escolar, es decir: Presentación de la Unidad, Desarrollo de la Unidad y Cierre de la Unidad. Después se observa la Inclusión Simbólica, que tiene una frecuencia de aparición asociada a los diccionarios de 145, y su presencia en la estructura del texto se observa en la tres partes de la unidad, ya mencionadas, destacando su aparición en un titulo de contenido al interior del Desarrollo de la Unidad. Por dichos motivos, se observa que ambas Inclusiones se constituyen en el lado de la Relevancia de los escritos en los textos escolares.

Por otro lado, el análisis de la frecuencia de aparición más la ubicación en la estructura del texto escolar, permite decir que el sistema de opacidad de los escritos está formado por los campos semánticos que indican Inclusión Primaria y Heterorreferida.

La primera opacidad tiene que ver con la Inclusión Primaria, la que aparece asociada a la frecuencia de aparición de los diccionarios de 263 y se ubica sólo en una parte de la unidad, en el Desarrollo de la Unidad. Mientras que la Inclusión Heterorreferida, que le sigue, aparece en una frecuencia de 35 y se ubica sólo en la sección de Desarrollo de la Unidad.

\section{Ubicación de campos semánticos a nivel escritos sector Lenguaje y Comunicación}

De acuerdo a la estructura de los textos, los campos semánticos construidos a nivel de los relatos identificados del sector de Lenguaje y Comunicación, se ubican de la siguiente manera en la estructura del texto, es decir Inicio de la Unidad, Desarrollo de la Unidad, Cierre de la Unidad.

\begin{tabular}{|l|l|l|}
\hline Campos semánticas & Frecuencia & Ubicación texto \\
\hline Inclusión Secundaria & 63 & $\begin{array}{l}\text { Desarrollo de la Unidad: } \\
\text { - Personajes de cuentos } \\
\text { - Desarrollo de cuentos y lecturas }\end{array}$ \\
\hline Inclusión Heterorreferida & 65 & $\begin{array}{l}\text { Desarrollo de la Unidad: } \\
\text { - Personajes de cuentos } \\
\text { - Desarrollo de cuentos y lecturas }\end{array}$ \\
\hline Exclusión Heterorreferida & 3 & $\begin{array}{l}\text { Desarrollo de la Unidad: } \\
\text { - Desarrollo de cuentos. }\end{array}$ \\
\hline
\end{tabular}

Tabla No 8: Ubicación Campos Semánticos Nivel Escrito Sector Lenguaje y Comunicación

En base a la tabla anterior, se pudo distinguir el código "relevancia/opacidad" en función de la frecuencia de aparición de los campos semánticos, más la ubicación de ellos. Realizando este cruce, el sistema de relevancia/opacidad de los relatos del sector Lenguaje y Comunicación queda constituido de la siguiente manera: 


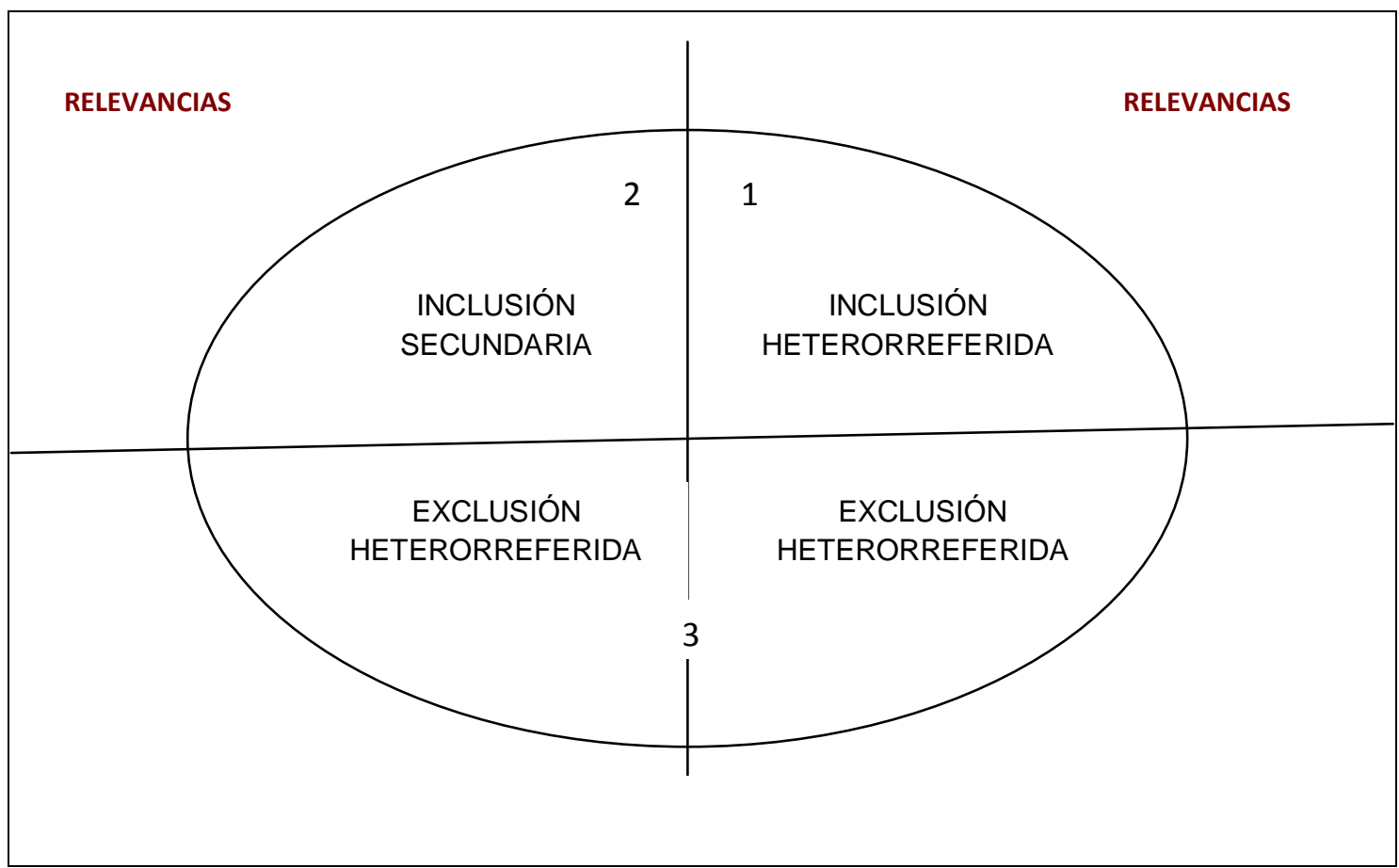

Gráfico No 2 Relevancia/Opacidad Nivel Escrito Sector Lenguaje

El análisis anterior, permite establecer que el sistema de relevancia de los relatos del sector Lenguaje y Comunicación está formado por los campos semánticos que señalan Inclusión Heterorreferida y Secundaria.

Como se observa, la primera relevancia está dada por el campo semántico referido a la Inclusión Heterorreferida, el que se construye sobre la frecuencia de aparición de 64, y se ubica en el Desarrollo de la Unidad. Mientras que el campo semántico de Inclusión Secundaria tiene una frecuencia de aparición de 63 y se ubica también en el Desarrollo de la Unidad.

Con respecto a la opacidad construida por los relatos del sector de Lenguaje y Comunicación, se observa que sólo está formado por el campo semántico de Exclusión Heterorreferida el que presenta una frecuencia de aparición de 3.

\section{Ubicación de campos semánticos a nivel Ilustraciones (63 textos)}

Los campos semánticos construidos a nivel de las ilustraciones, se vinculan a tamaños definidos para esta investigación, al interior del texto escolar, los que a su vez se asocian a la estructura del texto, es decir Inicio de la Unidad, Desarrollo de la Unidad, Cierre de la Unidad.

\begin{tabular}{|l|l|l|l|}
\hline Campos Semánticos & $\begin{array}{l}\text { Total Campos } \\
\text { Semánticos }\end{array}$ & $\begin{array}{l}\text { Tamaño } \\
\text { asociado }\end{array}$ & Ubicación texto \\
\hline Inclusión Heterorreferida & 101 & $\mathrm{~S}, \mathrm{M}, \mathrm{L}, \mathrm{XL}$ & $\begin{array}{l}\text { - Contenido de la Unidad } \\
\text { - Inicio de la unidad }\end{array}$ \\
\hline Inclusión Primaria & 135 & $\mathrm{M}, \mathrm{L}$ & - Contenido de la Unidad \\
\hline Inclusión Simbólica & 8 & $\mathrm{M}$ & - Contenido de la Unidad \\
\hline Inclusión Secundaria & 65 & $\mathrm{~S}, \mathrm{M}, \mathrm{L}, \mathrm{XL}$ & $\begin{array}{l}\text { - Contenido de la Unidad } \\
\text { - Inicio de la unidad }\end{array}$ \\
\hline Exclusión Secundaria & 19 & $\mathrm{M}, \mathrm{L}$ & $\begin{array}{l}\text { - Contenido de la Unidad } \\
\text { - Inicio de la unidad }\end{array}$ \\
\hline
\end{tabular}


Vejez y envejecimiento: Imaginarios sociales presentes en los textos escolares oficiales del Ministerio de educación chileno

\begin{tabular}{|l|l|l|l|}
\hline Campos Semánticos & $\begin{array}{l}\text { Total Campos } \\
\text { Semánticos }\end{array}$ & $\begin{array}{l}\text { Tamaño } \\
\text { asociado }\end{array}$ & Ubicación texto \\
\hline Exclusión Primaria & 18 & S, M & - Contenido de la Unidad \\
\hline \multicolumn{2}{|r}{ Tabla No 9: Ubicación Campos Semánticos Nivel Ilusraciones } \\
\hline
\end{tabular}

En base a la tabla anterior, se pudo distinguir el código "relevancia/opacidad" en función de la frecuencia de aparición de los campos semánticos, más la ubicación de ellos. Realizando este cruce, el sistema de relevancia/opacidad de las Ilustraciones en los textos escolares queda constituido de la siguiente manera:

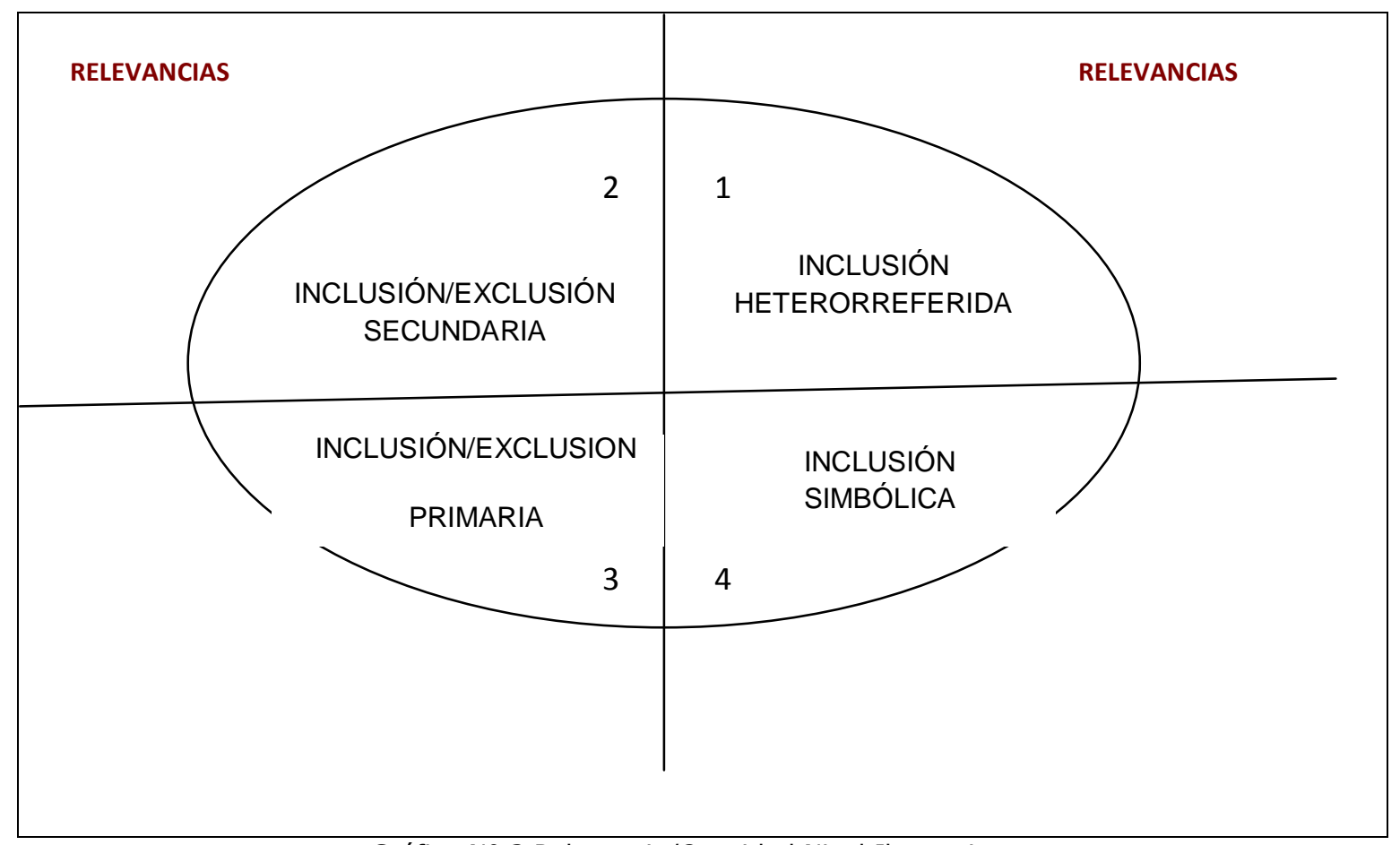

Gráfico No 3 Relevancia/Opacidad Nivel Ilustraciones

El análisis realizado sobre los elementos presentes en la tabla $N^{\circ} 9$, permiten establecer que el sistema de relevancia de las ilustraciones se forma de los campos semánticos Inclusión Heterorreferida e Inclusión/Exclusión Simbólica.

La máxima relevancia está dada por Inclusión Heterorreferida, su ubicación se explica por su frecuencia de aparición de 101 y por su expresión en los cuatros tamaños definidos para las ilustraciones. Estos tamaños permiten indicar que este campo semántico se asocia tanto al Inicio de la Unidad, como el Desarrollo de Contenido de ésta.

A su vez, se observa, que el campo semántico formado por la Exclusión/Inclusión Secundaria se posiciona al lado de la relevancia, puesto que lo referido a la Inclusión Secundaria está vinculada a una frecuencia de aparición de 65 y se asocia a los cuatro tamaños definidos en la investigación, lo que permite decir que se ubica en las tres partes que forman la unidad en los textos escolares. Mientras que el campo que refiere a la Exclusión Secundaria tiene una frecuencia de ilustraciones asociada de 19 y se presenta en dos de los tamaños lo que se asocia a la presencia en dos de las tres partes que componen las unidades de los textos escolares. Estas dimensiones son presentadas juntas en el análisis de las relevancias, puesto que apuntan hacia un 
mismo tipo de Inclusión y Exclusión además las cantidades y lugares en las que se presentan, permiten indicarlos en el lado de la relevancia de las Ilustraciones al interior de los textos escolares.

Por otro lado, la opacidad de las Ilustraciones al interior de los textos escolares, quedó formado por los campos semánticos de Inclusión/Exclusión Primaria e Inclusión Simbólica.

La primera opacidad está dada por la Inclusión/Exclusión Primaria, puesto que lo que refiere a la Inclusión Primaria aparece vinculada a 135 frecuencias de aparición las que se vinculan a dos tamaños asociados al Desarrollo de la Unidad, mientras que las ilustraciones que se relacionan a la Exclusión Primaria, aparecen 18 veces vinculadas a dos tamaños asociados al Desarrollo de la Unidad. Estas dimensiones son tratadas de forma conjunta, puesto que refieren a un mismo tipo de Inclusión y Exclusión, y por las frecuencias de aparición y lugares ocupados en la estructura de los textos escolares.

Finalmente, el último campo semántico que constituye la opacidad de las ilustraciones presentes en los textos escolares es Inclusión Simbólica, puesto que tiene una frecuencia de aparición de 8 y sólo aparece en un tamaño asociado al Desarrollo de la Unidad.

\section{Imaginarios sociales de la vejez y el envejecimiento, presentes en los textos escolares del MINEDUC}

Finalmente, después de la distinción del código "relevancia/opacidad" en los tres niveles de análisis utilizados, es decir: Nivel Escrito, Nivel Escrito sector Lenguaje y Comunicación y Nivel Ilustraciones, que permitió reducir la complejidad del tema estudiado y operacionalizarlo, a fin de develar los Imaginarios Sociales de le vejez y el envejecimiento presentes en los textos escolares oficiales del MINEDUC, se observa el siguiente comportamiento de los campos semánticos revisados: Inclusión/Exclusión Primaria, Inclusión/Exclusión Secundaria, Inclusión/Exclusión Simbólica e Inclusión/Exclusión Heterorreferida, en relación a los lugares ocupados dentro de la estructura del material empírico revisado:

\begin{tabular}{|c|c|c|}
\hline Campo Semántico & Frecuencia & Ubicación Texto \\
\hline $\begin{array}{l}\text { Inclusión/Exclusión } \\
\text { Secundaria }\end{array}$ & 492 & $\begin{array}{l}\text { Presentación de Unidad: } \\
\text { - Inicio de la unidad } \\
\text { - Breve Lectura de inicio } \\
\text { Desarrollo de la Unidad: } \\
\text { - Unidades referidas a la familia } \\
\text { - Personajes de cuentos } \\
\text { - Taller: dramatización } \\
\text { - Actividades individuales } \\
\text { - Ejercicios de aplicación; } \\
\text { - ejercicios matemáticos, vocabulario, gramaticales, } \\
\text { comprensión de lectura } \\
\text { - Desarrollo de cuentos y lecturas } \\
\text { Cierre de la unidad: } \\
\text { - } \quad \text { auto evaluación }\end{array}$ \\
\hline $\begin{array}{l}\text { Inclusión/Exclusión } \\
\text { Primaria }\end{array}$ & 416 & $\begin{array}{l}\text { Desarrollo de la Unidad: } \\
\text { - Actividad inicial } \\
\text { - Desarrollo de contendidos de unidad: reflexión } \\
\text { - Ejercicios de aplicación; ejercicios matemáticos, } \\
\text { vocabulario. }\end{array}$ \\
\hline
\end{tabular}

Revista Mad. No 22, Mayo de 2010. Departamento de Antropología. Universidad de Chile http://www.revistamad.uchile.cl/22/Jorquera_07.pdf 
Vejez y envejecimiento: Imaginarios sociales presentes en los textos escolares oficiales del Ministerio de educación chileno

\begin{tabular}{|c|c|c|}
\hline Campo Semántico & Frecuencia & Ubicación Texto \\
\hline $\begin{array}{l}\text { Inclusión } \\
\text { Simbólica }\end{array}$ & 153 & $\begin{array}{l}\text { Presentación de la unidad: } \\
\text { - Breve lectura de inicio } \\
\text { Desarrollo de la Unidad: } \\
\text { - desarrollo de contenido de unidad: reflexión } \\
\text { - } \quad \text { jercicios de aplicación matemáticos } \\
\text { personas mayores } \\
\text { - Percicios de aplicación: Actividad: conversar con } \\
\text { - } \quad \text { Desarrollo de cuentos y lecturas } \\
\text { - } \quad \text { actividades grupales } \\
\text { - } \quad \text { jercicios matemáticos } \\
\text { - } \quad \text { ctividades de aprendizaje: preguntas } \\
\text { Anexos: } \\
\text { - Proyecto de investigación } \\
\text { - Síntesis de la unidad } \\
\text { - } \quad \text { auto evaluación }\end{array}$ \\
\hline $\begin{array}{l}\text { Inclusión/Exclusión } \\
\text { Heterorreferida }\end{array}$ & 204 & $\begin{array}{l}\text { Presentación de la unidad: } \\
\text { - motivación e introducción } \\
\text { Desarrollo de la Unidad: } \\
\text { - Desarrollo de cuentos y lecturas } \\
\text { : Personajes de cuentos } \\
\text { vocabulario. }\end{array}$ \\
\hline
\end{tabular}

En base a lo anterior, y de acuerdo al objetivo general de la presente investigación, se pudo develar los imaginarios sociales en torno a la vejez y el envejecimiento presentes en los textos escolares oficiales del MINEDUC desde pre kinder a cuarto medio, el cual quedó constituido de la siguiente manera:

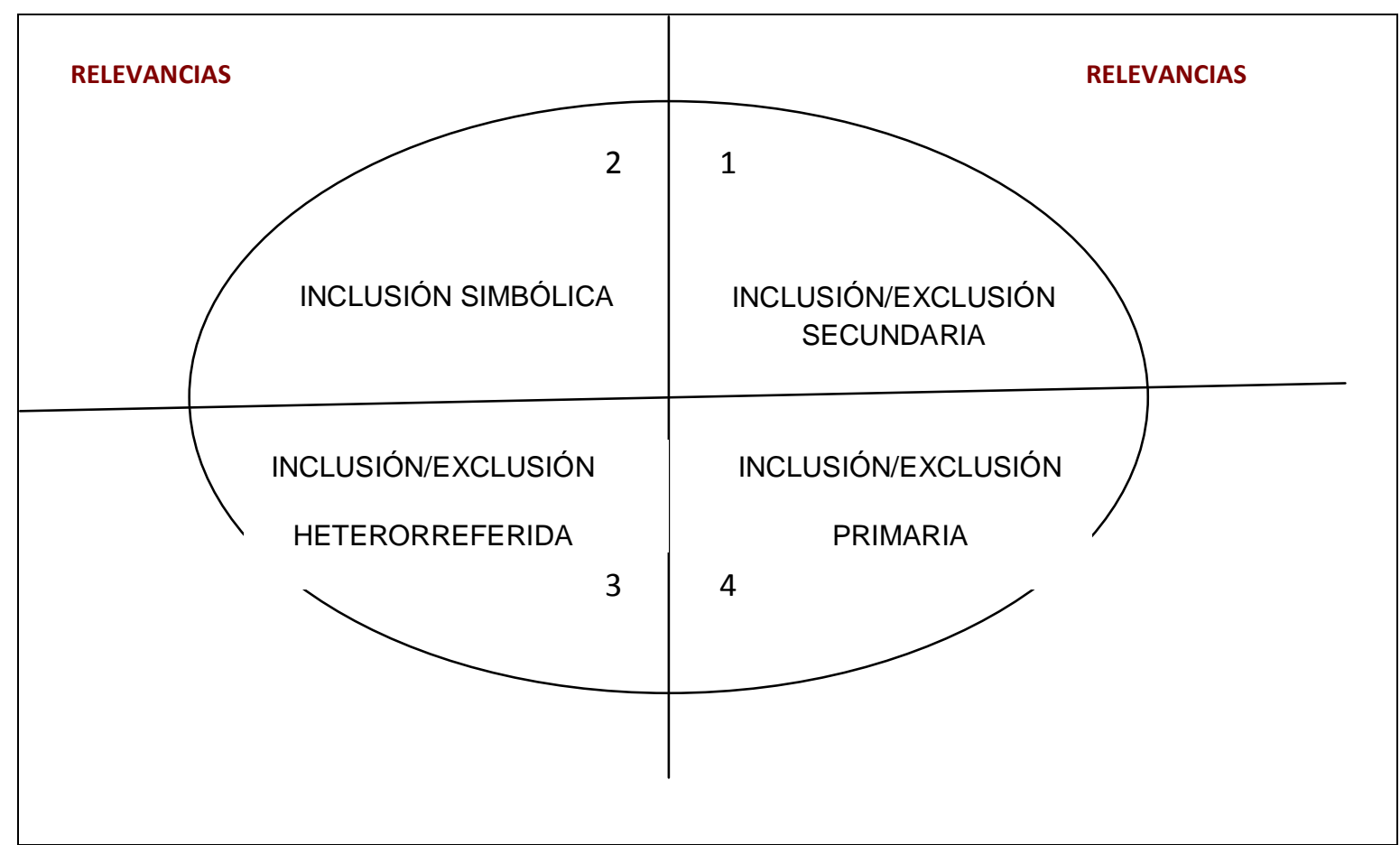

Gráfico No 4: Imaginarios Sociales Textos Escolares 
De acuerdo al modelo operativo de los Imaginarios Sociales (Pintos: 2003) utilizado, se observa como la realidad en torno a la vejez y el envejecimiento es construida en los textos escolares del MINEDUC. Siguiendo la metáfora de Pintos para su explicación, el código "relevancia/opacidad" es una distinción que funciona como un foco de una cámara fotográfica, graba lo visible, lo que aparece en el campo y lo que queda fuera del campo, y por lo tanto invisible desde la posición que asume la cámara (Pintos: $2003,20)$ De esta manera se observa que el foco de la cámara con la cual se observa la vejez y el envejecimiento de los textos escolares, graba la parte visible de estas temáticas en los campos semánticos que se ubican en el lado de las relevancias, es decir Inclusión/Exclusión Secundaria e Inclusión Simbólica, mientras que la opacidad, es decir, lo que queda fuera del campo de observación es lo que refiere a la Inclusión/Exclusión Heterorreferida y Primaria.

\section{Conclusiones y reflexiones finales}

La investigación descrita ha tenido como principal objetivo develar los imaginarios sociales de la vejez y el envejecimiento presentes en los textos escolares oficiales del Ministerio de Educación chileno. Los resultados encontrados, coinciden con los resultados alcanzados por otras investigaciones realizadas en el tema, sin embargo la particularidad de ella radica en su vinculación y tratamiento desde el enfoque de la Inclusión/Exclusión.

En relación a lo anterior, se debe precisar que el enfoque mencionado, no observa dichos fenómenos como excluyentes, sino como diferentes formas de expresión del comportamiento de los sistemas funcionales. Al ser la sociedad actual funcionalmente diferenciada, promueve las especializaciones de las operaciones asumidas por los diferentes sistemas sociales, puesto que el nivel de complejidad alcanzado por ella hace imposible que exista un solo centro capaz de sobrellevarla. Por lo tanto no se puede estar incluido o excluido completamente de la sociedad, ya que si bien se puede estar excluido de algún sistema, se puede estar incluido en otros al mismo tiempo. Lo que evidencia la complejidad del fenómeno estudiado.

Con respecto a los Imaginarios relacionados con la vejez, se evidencia que en los textos escolares existe una mayor representación de la vejez que del envejecimiento. En este sentido la vejez es construida como una etapa específica del ciclo vital, incluida de forma secundaria, el análisis efectuado permite observar con claridad que la mayor presencia de la vejez se produce por la figura de los abuelos/as. Este imaginario construido en torno a la vejez, se presenta como una realidad naturalizada, aceptándose de forma explicita, no poniéndose en juicio en ningún momento. De esta manera las personas que viven la etapa de la vejez constituirían un aporte a la sociedad en la medida que cumplen la función de abuelos.

Con respecto a las relaciones sociales (parte de la Inclusión Secundaria), y estrechamente relacionado con lo anterior, se observa la cercana relación social establecida entre los niños/as y los adultos mayores. De acuerdo a esto, la principal generación con la cual interactúan las personas que viven la etapa de la vejez son los niños, ya sea que se manifiesten como sus propios nietos o niños en general. Esta relación se presenta como una relación armónica y repleta de amor, en donde cada uno disfruta y aprende del otro. No obstante cuando los nietos crecen y se convierten en jóvenes o adolescentes, la relación cambia hacia un estado de constante tensión, fundada en las formas de ser de cada uno de los grupos generacionales; el desinterés de los jóvenes $\mathrm{v} / \mathrm{s}$ la rigidez de los viejos, y por lo que cada etapa vital representa, el 
apogeo de la vida en la juventud v/s la decadencia de la vejez. Cabe precisar que las relaciones sociales con la generación adulta y con sus propios pares no son un tema que aparezca en los textos escolares, los primeros sólo aparecen mediando entre los abuelos y los nietos pero no desarrollando un mayor vínculo con los adultos mayores, mientras que las relaciones entre los pares prácticamente no aparecen en los textos escolares, mayormente los adultos mayores no se muestran relacionándose con personas de su misma edad y cuando se presenta se les muestra al interior de las familias, en sus roles de abuelos o al interior de hogares de ancianos como adultos mayores institucionalizados.

Aun cuando los textos escolares muestran la Inclusión secundaria descrita anteriormente, es posible observar, al mismo tiempo, la presencia de ámbitos de exclusión secundaria, referido principalmente a la presencia de adultos mayores en estado de abandono social, es decir alejados de redes sociales, inclusive de los familiares.

Por otro lado, en relación a la vejez, los textos escolares muestran la Inclusión/Exclusión de tipo Heterorreferida en la que, si bien existe una mayor parte de alusiones, percepciones, sensaciones y expectativas en torno a la vejez de forma inclusiva, es decir que no se consideran como aspectos negativos, se evidencia la presencia de ciertos estereotipos, ya sea en la forma de representar gráficamente la vejez (canas, anteojos uso de bastón, etc.) o en las características psicológicas de los adultos mayores, y lo que les está permitido hacer socialmente, las que se utilizan como forma de diferenciar de las demás etapas de la vida. Además se observa, si bien en mucha menor medida que la presencia de la Inclusión Heterorreferida, la Exclusión Heterorreferida, expuesta en el uso de lenguaje estereotipo que ilustra los modismos negativos utilizados por las personas en la vida cotidiana y que expresan y fortalecen los ámbitos de exclusión de la vejez, reforzando las aprensiones que rodean a las temáticas estudiadas.

Finalmente con respecto a la vejez, se constata en el análisis realizado a los textos escolares oficiales del MINEDUC, que esta etapa de la vida es incluida en los sistemas funcionales de la sociedad, es decir a nivel Primario, pero cuando esto sucede se le hace en posiciones periféricas como por ejemplo el caso del Sistema Económico en donde se les incluye a nivel de pensionados o jubilados o en relación a la inclusión de las políticas públicas. Además se constata, en base a los análisis realizados, que los textos escolares construyen ámbitos de Exclusión de tipo Primaria, por ejemplo lo relacionado con las generaciones y el trabajo. En conclusión se observa que en lo que refiere a la Inclusión/Exclusión Primaria, la vejez sería el tema con el que menos se le asocia en los textos escolares.

Con respecto a las formas de expresión del envejecimiento, se observa que este se presenta como el proceso natural que se inicia con el nacimiento y culmina con la muerte. No obstante, las referencias a él se mantienen dentro de indicaciones generales, cuyo fin es ordenar y clasificar la estructura social, por un lado, mientras que por otro se utiliza como una forma de mostrar los cambios degenerativos y biológicos y los desafíos que impone al sistema social. Es así como lo referente al envejecimiento se presenta como un ámbito de Inclusión Simbólica, ya que sólo se mantiene en el dominio de la indicación y descripción de la condición de dicho proceso.

En síntesis, se observa que la relevancia de los Imaginarios Sociales se ubica en lo que se definió como Inclusión/ Exclusión Secundaria, es decir la Inclusión de la vejez y el 
envejecimiento se relaciona principalmente a los espacios que refieren a las redes e interacciones sociales que los adultos mayores puedan desarrollar al interior de las familias mediante la figura del abuelo/a. Esta forma de mostrar la Inclusión Secundaria deja fuera las relaciones sociales que los adultos mayores pueden establecer con amigos o grupos de su misma edad, las relaciones de pareja en la vejez, entre otras. Encasillando y asociando la vejez sólo a la figura del abuelo/a. No obstante a lo anterior, muchas de las apariciones de las familias en los textos escolares, no incluyen la figura del abuelo/a de forma cotidiana, sino que se utiliza para caracterizar un tipo de familia en particular (extendida) la que es presentada como algo atípico.

La inclusión simbólica también se ubica en el lado de las relevancias, lo que permite decir que la otra forma de incluir a la vejez y el envejecimiento en los textos escolares, es el mero reconocimiento de su presencia al interior de la sociedad, mediante su indicación a nivel social. En este sentido se reconoce como inclusivo que en los textos escolares se haga mención a los procesos de envejecimiento que está viviendo, tanto la sociedad mundial como nacional, sin embargo, esto no traspasa el terreno del reconocimiento a nivel discursivo, no mostrándose espacios de desarrollo u oportunidades efectivas en las cuales se puedan desenvolver.

Con respecto a la manifestación del fenómeno de la Inclusión/ Exclusión en el terreno de las opacidades, el estudio realizado mostró como dentro de ellas se observa la Inclusión/ Exclusión Heterorreferida, la que alude a las percepciones, sensaciones o expectativas sobre la vejez y el envejecimiento por parte de terceros. La inclusión/ Exclusión de este tipo se expresa en los textos por medio de las caracterizaciones que se hacen en torno a estos fenómenos, los que si bien pueden considerarse como Inclusivos, porque surgen como características positivas sobre la vejez y el envejecimiento, como por ejemplo lo que refiere a la sabiduría, bondad presente en esta etapa. También se observan ciertos elementos que denotan los estereotipos presentes en la sociedad con respecto a la vejez, como la utilización que se hace de los conceptos asociados a la vejez con características negativas o en forma despectiva como: "iviejo verde!"

La inclusión/ Exclusión Primaria corresponde a la dimensión con menor presencia en los textos escolares, lo que permite indicar que los ámbitos de inclusión formal de la vejez y el envejecimiento no se presentan como un tema de importancia, sino que explícitamente se les excluye de ámbitos prioritarios de la sociedad, como lo es el mundo laboral.

Lo planteado anteriormente permite decir que los ámbitos de Inclusión/Exclusión de la vejez y el envejecimiento en los textos escolares se caracterizan por ser de tipo parcial y negativa, configurando espacios restringidos y acotados de desarrollo de ambas temáticas.

Como se observa queda totalmente fuera de los textos escolares la visión de los adultos mayores como personas autónomas y dueñas de su propio destino, con poder de decisión para desenvolverse en otras áreas que no sea la esfera familiar; por ejemplo no se muestra la creciente incorporación de los adultos mayores en el sistema de la educación, a través de la serie de ofertas educativas que algunas universidades, tanto a nivel nacional como internacional, poseen. También quedan fuera de los Imaginarios Sociales los adultos mayores que no son abuelos, los que no tienen hijos ni nietos (ya sea por decisión propia o no), la realidad de los adultos mayores homosexuales, la vejez étnica, puesto que si bien se muestran ilustraciones que representan población mapuche, no se muestran otros tipos de etnias o grupos de 
emigrantes que viven en nuestro país. Tampoco se muestran las diferencias etáreas que existen al interior del mismo grupo adulto mayor, es decir, todos los adultos mayores son agrupados en la misma categoría social, sin distinguir que las necesidades y potencialidades que se tienen a los 65 años son muy diferentes de las que se presentan a los 90 años.

De esta manera se advierte que el código de "relevancia/opacidad" de los Imaginarios de la vejez y el envejecimiento presentes en los textos escolares utiliza la distinción "tradicional/moderno". En este sentido la vejez y el envejecimiento son valorados y relevados en lo que refiere al Mundo Tradicional. Cumpliendo la función de mantener, cuidar y enseñar a la sociedad, indicándole sus límites y lo que no debe olvidar para dejar de existir. Por eso se explica su continua manifestación en los ámbitos familiares (como abuelos) la fuerte vinculación entre vejez y cultura mapuche y la alta presencia de ilustraciones que denotan sabiduría legitimada. Cuando las temáticas estudiadas se presentan dentro de este Mundo Tradicional surgen y se valoran sus mayores aportes a la sociedad y, por lo tanto, se presentan los ámbitos en los cuales la sociedad los incluye. Esto permite decir que los tipos de inclusión/exclusión que relevan los textos sean las de tipo Secundaria y Simbólica.

Al contrario, cuando las formas de expresión de la vejez y el envejecimiento se alejan de los roles al interior del Mundo Tradicional, y se acercan a lo Moderno las formas de Inclusión aparecen parciales y las de Exclusión patentes.

Lo anterior cobra importancia si nos detenemos en la definición de los Imaginarios Sociales elaborada por Pintos (2000) como: esquemas, construidos socialmente, que nos permiten percibir algo como real, explicarlo e intervenir operativamente en lo que en cada sistema social se considera como realidad. Como constructores de orden social, rigiendo las representaciones colectivas de identificación e integración social.

Puesto que la realidad social no refiere a un solo tipo que podamos distinguir como la realidad sino que se constituye de muchas realidades dependiendo del observador, los Imaginarios Sociales presentes en los textos escolares permitirían reducir la complejidad propia de la realidad social, proporcionando un esquema de distinción que ordena, explica y nos permite intervenir en lo que se observa como real. De esta manera los Imaginarios Sociales de los textos escolares, van configurando una determinada forma de construir la vejez y el envejecimiento, la que se caracteriza por los ámbitos de Inclusión y Exclusión ya descritos.

Es así como, por medio de los textos escolares, el sistema educativo va reproduciendo los Imaginarios de la vejez y el envejecimiento, los que a su vez van restringiendo los ámbitos de desarrollo de ambas temáticas, comprendiendo a la vejez como una etapa del ciclo vital naturalizada en la que la principal función es el mantenimiento de las tradiciones culturales ilustradas en la figura de los abuelos.

Además condiciona ámbitos de inclusión y exclusión de las temáticas estudiadas, no sólo de los estudiantes a los que esta dirigido el texto, sino también de los profesores que trabajan en base a ellos, a las familias de los estudiantes, y a la larga de los mismos adultos mayores, quienes van asumiendo las comunicaciones que se van reproduciendo en la sociedad sobre ellos y su condición. En palabras de Pintos, "la realidad de las consecuencias no deriva de la realidad de los antecedentes sino de la capacidad creativa o credencial de los actuantes" (Pintos, 2003, 4), en tal sentido los 
Imaginarios Sociales descritos fabricarían realidades que predispondrían la percepción y el surgimiento de las creencias en torno a la vejez y el envejecimiento.

Al ser el texto escolar el principal dispositivo utilizado por el sistema educativo, representa lo que la sociedad aprueba legítimamente y encuentra importante de traspasar a las nuevas generaciones para que éstas, al llegar a la adultez, reproduzcan y transmitan. En tal sentido es muy importante detenerse a analizar cuales son los temas con los cuales se esta asociando la vejez y el envejecimiento en ellos, ya que dichas formas de entenderla condicionaran las formas en que son tratados por los estudiantes en su vida diaria.

Es importante presentar a la vejez y el envejecimiento como un proceso natural de la vida y que depende de cada uno como sea vivida. Al presentarla como algo cercano y digno de ser vivido, al igual que otras etapas vitales

Es prioritario que se derrumbe la visión que existe una sola manera de ser viejo, en la que se deben cumplir los roles sociales ya descritos, sino que existen tantas vejeces como observadores que la construyan. Además debe mostrarse con una cara más amigable y atrayente, si bien no se desconoce el alto nivel de abandono y de vulnerabilidad en la que viven muchas personas mayores en nuestro país, esta condición no debe ser explotada a la hora de buscar familiaridad ni identificación con la temática, puesto que la crudeza de esta situación produce la evasión y la negación de dichas realidades, no permitiendo que haya una visión positiva de la vejez, que invite al trabajo en conjunto, sino que de decadencia y decrepitud, que promueve el ensimismamiento en la propia realidad.

De tal forma, se dejará de ver la vejez y el envejecimiento como un sino trágico al cual nadie quiere llegar, sobre todo en nuestra sociedad en donde hay una alta valoración de la juventud y la belleza y se le podrá observar como una etapa con sus desventajas pero también ventajas.

Lo anterior es imperativo en una sociedad, como la chilena, que se encuentra en un fuerte proceso de envejecimiento social, en donde se vislumbra que en unos años la población adulta mayor aumentará. Es preciso no sólo comunicar un Imaginario de la vejez y envejecimiento que no merme los ámbitos de inclusión de los actuales adultos mayores, sino también un imaginario que prepare a las nuevas generaciones a enfrentar una larga vida. Una forma de hacerlo es presentar un Imaginario Social más diversificado y positivo en los medios de difusión masiva que tienen las sociedades, como lo es el texto escolar.

Lo anterior permitirá que la sociedad observe la vejez y el envejecimiento como un fenómeno socialmente construido, y por tanto que se reflexione sobre las formas de operar que posee y sobre las consecuencias que esto conlleva. Permitiendo ampliar las esferas de inclusión de este, cada vez más creciente, grupo social, tanto en cantidad como en calidad de los espacios. RM

\section{Bibliografía}

Abarca, M. (1993): Vejez: entre imagen y realidad: estudio etnográfico sobre la participación de los adultos mayores en organizaciones. Tesis para optar al título de asistente social. Universidad Católica de Chile, Santiago, Chile. 
Andréu, J. (2000). Las técnicas de análisis de contenido; una revisión actualizada. En http://public.centrodeestudiosandaluces.es/pdfs/S200103.pdf Visitado el 16 de Junio de 2009.

Araníbar, P. (2001): Acercamiento conceptual a la situación del adulto mayor en América Latina. Serie Población y Desarrollo no 21. CELADE- CEPAL. Santiago de Chile.

Arcos E., Molina I., Fecci E., Zúñiga Y., Márquez M., Ramírez M., Miranda C., Rodríguez L. y Pobrete J. (2003- 2004): Descubriendo el género en el currículo explicito (currículo formal) de la educación de tercer ciclo, Universidad Austral de Chile.

Arnold, M. (1998): Introducción a los Conceptos Básicos de la Teoría General de Sistemas. Cinta de Moebio $\mathrm{N}^{\circ}$ 3. Facultad de Ciencias Sociales. Universidad de Chile. Disponible en http://www.moebio.uchile.cl/03/frprinci.htm visitado el 27 de enero de 2010.

Arnold, M. (2003): Fundamentos del Constructivismo Sociopoietico. Cinta de Moebio No 18. Santiago: Universidad de Chile.

Arnold, M. (2006): Fundamentos de la observación de segundo orden. En Manuel Canales Cerón (coordinador- editor). Metodologías de Investigación Social introducción a los oficios (pp. 321-348). Chile: LOM ediciones.

Arnold, M., Thumala, D., Urquiza, A., y Ojeda, A. (2007): La vejez desde la mirada de los jóvenes chilenos: estudio exploratorio. Ultima Década № 27, CIDPA Valparaíso, diciembre 2007, pp. 75-91.

Arnold, M., Thumala, D., Urquiza, A., Ojeda, A., y Vogel, N. (2008): Sexualidad en la tercera edad. "La imagen de los jóvenes universitarios". Pronto-e-vigula, Dossiê Juventudes: práticas político-culturais e alinhamentos metodológicos. Revista do programa de estudos pós-graduados em ciências sociais da puc-sp, 4; 358-374.

Arnold, M., Thumala, D., Urquiza, A. y Ojeda, A. (2007): Exclusión social de los adultos mayores. Congreso XXVI Asociación Latinoamericana de Sociología (Alas). Guadalajara, México, 22-26 agosto.

Arnold, M., Thumala, D., Urquiza, A. y Ojeda, A. (2009): "Inclusión y Exclusión social del Adulto Mayor en Chile. Opiniones, expectativas y evaluaciones de la población chilena sobre diferentes modalidades de inclusión y exclusión social de las personas adultas mayores" en http://www.esistemicosvejez.cl/upload/est_pdf/5.pdf.

Comité Nacional para el Adulto Mayor. (2002): Encuesta Imagen de la Vejez. Gobierno de Chile. Santiago: Chile. Disponible en: http://www.Stevenson.cl/Archivos/716.pdf visitado el 28 de abril de 2009

Cuadra, S. (2005): Participación laboral de hombres adultos mayores. Tesis para optar al título de Ingeniero. Universidad de Chile, Santiago, Chile.

Cuddy, A., Norton, M. \& Fiske, S. (2005): This old stereotype: The pervasiveness and persistente of the elderly stereotype. Journal of Social Issues, Vol $61, \mathrm{~N}^{\circ} 2 \mathrm{pp}$ 267-285 
Díaz, Á. (2005): La educación en valores: Avatares del currículo formal, oculto y los temas transversales. Revista electrónica educativa, 8; 1, 2-15.

Gastrom, L., Vujosevich, J. y Oddone J., (2003): La vejez como objeto de las representaciones sociales. En Libro: Jornadas Gino Germani, IIFCS, Instituto de investigaciones Gino Germani, Buenos Aires. Disponible en www.//bibliotecavirtual.clacso.org.ar/ar/libros/argentina/germani/gastron.rtf visitado el 10 de mayo de 2009

Fernández, P., (2008): Experiencia del Hogar de Cristo con adultos mayores en situación de exclusión social: avances y desafíos. En Construyendo políticas públicas para una sociedad que envejece (pp. 75-101). Chile.

Hardy, M. (2003): Older workers. En R. Binstock and L. George (Eds.), Handbook of aging and the social sciences (pp 202-218). United States of America: Academic Press

Hernández, R. y Sampieri, H. (1997): Definición del tipo de investigación a realizar: básicamente exploratoria, descriptiva, correlacional o explicativa. En Metodología de Investigación. (pp. 59-72) McGRAW-Hill

Martens, A., Goldenberg, J. \& Greenberg, J. (2005): A terror management perspective on Ageism, Journal of Social Issues, 61:2, 223-239.

Monchietti, A., y Sánchez, M. (2008): Acerca de la génesis de la representación social de la vejez. Revista Argentina de Sociología Año 6 No 10

Monchietti, A., Lombardo, E. y Sánchez, M. (2007): Representación social de la vejez en niños y púberes. Limite, Revista de Filosofía y Psicología, 2; 16, 71-81.

Morgado, V. (2001): Sexualidad en el adulto mayor institucionalizado. Tesis para optar al título de Psicóloga, Universidad del Desarrollo, Santiago, Chile.

Oddone, J. (2003): La vejez como objeto de las representaciones sociales. En Libro: Jornadas Gino Germani, IIFCS, Instituto de investigaciones Gino Germani, Buenos Aires. Disponible enwww.//bibliotecavirtual.clacso.org.ar/ar/libros/argentina/germani/gastron.rtf visitado el 10 de mayo de 2009

Oddone, J. (1998): La vejez en la educación básica argentina. En Leopoldo Salvarezza (Compilador). La vejez una mirada gerontológica actual (pp. 53-73) Argentina: Paidos.

Okoye, U. (2004): Knowledge of aging among secondary school students in southeastern Nigeria, Educational Gerontology, 30:6, 481-489.

Osorio, P. (2006): Exclusión Generacional: La Tercera edad. Revista MAD No 14, Mayo 2006. Departamento de Antropología Universidad de Chile en http://www.revistamad.uchile.cl/14/osorio.pdf, visitado el 28 de mayo 2009.

Oyarzún, L. (2004): Significado afectivo social y cultural atribuido a los textos escolares de lenguaje y comunicación distribuidos por el MINEDUC. Tesis magíster en educación. Universidad de Chile, Santiago, Chile. 
Pintos, J. (2000): Construyendo realidad (es): los imaginarios sociales en http: //web.usc.es/ jlpintos/articulos/construyendo.htm, visitado el 26 de mayo de 2009.

Pintos, J. (2006): Comunicación, construcción de realidad e Imaginarios Sociales en http: //www.usc.es/cpoliticas/mod/book/print.php?id=782, visitado el 8 de octubre de 2009.

Pintos, J. (2007): Algunos Imaginarios Sociales de la vejez en http://gceis.net/node/101, visitado el 5 de enero de 2010.

Ramírez, T. (2003): El texto escolar: una línea de investigación en educación. Revista de Pedagogía v 24 n 70 Caracas.

Robles, F. (2003): Contramodernidad y desigualdad social: individualización e individuación, inclusión/exclusión y construcción de identidad. La necesidad de una sociología de la exclusión, Revista Mad: Revista del Magíster en Antropología y Desarrollo, No. 12, 2005 En http://www.revistamad.uchile.cl/12/paper02.pdf

Rodríguez, D y Arnold, M. (1991): Sociedad y Teoría de Sistemas, Editorial Universitaria, Santiago de Chile.

Sánchez, A. (2004): El androcentrismo científico: el obstáculo para la igualdad de género en la escuela actual. Educar 29, pp. 91-102

Stevenson, A. (2006): Estudio de Posicionamiento del valor social del adulto mayor en los textos escolares de educación básica. Servicio Nacional del Adulto Mayor. En http://www.Stevenson.cl/archivos/TEXTOSESCOLARES.pdf visitado el 10 de mayo 2009.

Tan, P., Zhang, N. \& Fan, L. (2004): Students 'attitudes toward the elderly in the people's republic of China, Educational Gerontology, 30:4, $305-314$.

Thumala, D., Arnold, M., Urquiza, A., Ojeda, A. (2007). Las Nuevas Exclusiones: la marginalidad de la vejez. Memorias Congreso Anthropos 2007. Congreso Iberoamericano de Antropología. La Habana, Cuba. ISBN 959-282-043-0I.

Torrejón, M. (2007): Imaginario social de la vejez y el envejecimiento Análisis de Contenido de Prensa Escrita: El Mercurio, Las Últimas Noticias y La Cuarta. Tesis para optar al grado de Magíster en Antropología y Desarrollo. Universidad de Chile, Santiago, Chile. en http://www.observa.uchile.cl/tesis_torrejon.pdf visitado el 24 de abril de 2009.

Troncoso, D. (2001): Vejez y envejecimiento desde la perspectiva de género. Tesis para optar al título de Socióloga. Universidad de Chile, Santiago, Chile.

Vera, L., Rojas, P, Moya, M. Godoy, E. Salinas, M., Duarte, L., Cartes, S. (2004): Sexualidad para adultos mayores. Documento de trabajo, Universidad de Chile, Santiago, Chile.

Zapico, H. (2006): O binomio persoas maiores e libros de texto, A imaxe e concepto de vellez no curriculum escolar, Comunicación e Persoas Maiores, 4; 257- 265. En 
http://www2.xornalistas.org/mediateca/observatorio/xornadas/200702/comunicacions /artigo23.pdf visitado el 6 de abril de 2009 